\title{
Accounting for Fleet Heterogeneity in Estimating the Impacts of Large-Scale Fishery Closures
}

\author{
Dépalle Maxime ${ }^{1,}{ }^{*}$, Thébaud Olivier ${ }^{2}$, Sanchirico James N. ${ }^{3}$
}

1 University of California, Davis

2 Unité d'Economie Maritime

${ }^{3}$ University of California, Davis, and Resources for the Future

* Corresponding author : Maxime Dépalle, email address : $\underline{\text { mdepalle@ucdavis.edu }}$

\begin{abstract}
:
To date, the empirical literature on spatial closures has focused on specific fleets and/or areas, and relatively less attention has been paid to the evaluation of responses to large-scale spatial restrictions on ocean fishing. Where such restrictions occur, a broad range of fleets may be affected, with diverse response mechanisms determining the redistribution of fishing effort and the associated welfare impacts. We propose a methodological approach to address such situations. Using hypothetical scenarios regarding the closure of the UK exclusive economic zone (EEZ) to a diverse subset of French vessels as an example, we develop a spatial discrete choice model that incorporates the possibility to adjust the resolution of choice sets at the fleet level to account for heterogeneous behavioral patterns across fleets. We show how neglecting fleet diversity in the choice of the spatial resolution of analysis may bias the results of an impact study on large spatial closures.
\end{abstract}

Keywords : Discrete choice model, spatial closures, spatial resolution, VMS, welfare analysis. 


\section{Introduction}

With the development of marine spatial planning and the growing enclosure of the maritime domain, spatial restrictions have become popular for allocating access to maritime areas and resources (Collie et al., 2013; Sanchirico et al., 2010). This includes restrictions on commercial fisheries for biodiversity conservation (with the implementation of marine protected areas), fisheries management measures (seasonal closures, TURFs), or the access to other uses of the marine areas (e.g., aquaculture, maritime transport, renewable energy farms). The impacts of spatial restrictions on fisheries are complex and multi-dimensional, with consequences in the ecological, socio-economic, and political realms (Eagle et al., 2008). While conservationists have widely praised ecosystem-based approaches (FAO, 2009; Pikitch, 2004), they may be hard to implement in practice, because of a mismatch with the scale and scope of policies, or because of the lack of institutions able to resolve ocean-uses externalities (Sanchirico et al., 2010; Scott, 1955; Sievanen et al., 2011). Many have called for a better and systematic identification and assessment of trade-offs in maritime activities as a pre-requisite for the success of marine spatial plans (Collie et al., 2013; Jones, 2016; Sanchirico et al., 2010).

Stakeholders involved in the development and implementation of large-scale spatial closures often focus primarily on the immediate economic consequences of such measures. Provided the data are available, what could be called "first-order" effects can be easily evaluated by identifying lost catch possibilities and valuing them at their current landing prices, taking into account price variations across species, gear and areas from which the catches originate. However, the overall economic impacts of spatial closures are likely to be determined by intricate secondary and higher order effects (see section A of the Appendix section). The greatest 
of these effects is from fishers adapting to the new regulations in an attempt to mitigate impacts on their fishing enterprise (Branch et al., 2006; Fuller et al., 2017; Fulton et al., 2011).

With the increased availability of information on the spatial distribution of fishing activities, discrete-choice models (DCMs) of fishing location choices have become established as a powerful and popular framework for modelling spatial and temporal fishing behavior (Eales and Wilen, 1986; Smith, 2010). DCMs can both identify the patterns of fishing effort reallocation induced by the changes in accessible fishing areas, and measure the likely welfare implications of the changes ${ }^{1}$.

However, the literature on the response of fishing fleets to spatial closures has largely focused on specific fleets and/or areas. Relatively less attention has been paid to the evaluation of responses to largescale spatial restrictions on ocean fishing, where multiple fleets are simultaneously impacted. In most cases, spatial effort restrictions apply uniformly to all fishing activities, regardless of the diversity of fishing activities that often co-exist in a fishery. The implication is that a broad range of fishing fleets may be affected, with diverse response mechanisms determining the potential redistribution of fishing effort and associated welfare impacts. Soulié \& Thébaud (2006) have shown for instance that the costs of a fishing ban may be either exacerbated or mitigated depending on vessels' levels of mobility and polyvalence (i.e., ability to change métiers or targeted species) and the status of fishing opportunities in the areas surrounding the area closed to fishing. Therefore, neglecting fleet heterogeneity in the evaluation of the impacts of a fishing closure may strongly bias the evaluation.

We develop a methodological approach to integrate the diversity of fishing activities and associated behavioral patterns. Using potential access restrictions to the UK EEZ for foreign vessels following Brexit as a case study, and considering hypothetical scenarios regarding a large scale closure to 
a subset of French vessels operating in the North East Atlantic region between 2012 and 2015, we develop a spatial DCM that we estimate independently for each affected fleet segment. In doing so, we allow each segment to have its own spatial choice definition to account for the diversity of effort allocation patterns across fleets. Following Depalle et al. (under review) - which also estimate the same DCM using choice sets with a decreasing spatial resolution but focus only on a single specific fleet segment (longliners) -, and using fine resolution data on the allocation of fishing activity across a range of different fishing fleets, the model is used to estimate the potential reallocation of fishing effort under various assumptions regarding the definition of the choice sets at fleet level. We show how applying a one-size-fits-all choice of the spatial resolution of analysis across a diverse set of fleets may bias the results of a study on the welfare impacts from a large scale closure.

The paper is organized as follows. First, we present our approach to assess the response of fleets with different fishing patterns to the same, large-scale, spatial closure. Next, the fleets considered for the analysis are described, using the available data for a subset of French fleets operating in the North-East Atlantic area. We then describe the model predictions on how vessels would react to the closure and how predictions may vary according to the assumptions regarding spatial resolution of the choice set for each fleet. Finally, we discuss our results providing suggestions to further investigate the full consequences of large-scale spatial closures on multispecies, multi-fleet fisheries.

\section{Methods}

The evaluation of the impacts of closure scenarios on the fleets is carried out in two stages: first, to elicit the expected first-order impacts on landings, we determine the level of dependency of the example fleet to the areas that could be closed, and characterize this 
dependency in terms of the existence of alternatives for the impacted vessels; second, we consider the higher order consequences of likely adjustments in effort allocation of the fleet segments in the areas expected to remain accessible.

\section{First-order impacts}

In order to identify potential heterogenous patterns of dependency to the fishing areas that are to be closed, we begin by clustering the impacted fishing fleet by groups of vessels thereafter "fleet segments" - that share similar fishing métiers, defined as combinations of vessel sizes, gear types and target species (Girardin et al., 2015). Using data at the highest level of

spatial aggregation available $\left(\frac{1}{20}^{\circ} \times \frac{1}{20}^{\circ}\right.$ statistical squares), we sum catches and revenues from areas inside or outside closed waters and we compute - on a yearly basis over a baseline period from 2012 to 2015 - the share of fishing effort, catches and catch value from each area at the levels of vessels and fleet segments ${ }^{2}$. This enables us to rank vessels by their level of dependency on the closed areas, in terms of the landed catches and landings' value, and to identify the vessels most exposed to the closure scenarios. We further refine the typology of vessels that depend highly on the fishing areas to be closed by considering whether they exhibit specific patterns of activity that would distinguish them from the rest of the fleet. Clustering the analysis at the fleet segment level, we investigate potential correlations between a vessel's share of gross revenue from the fishing grounds to be closed and its technical characteristics (power and length), trips characteristics (average landing, landing's value and associated fishing effort), fishing efficiency (average catch and value per unit of effort, abbreviated as CPUE and VPUE), landing prices received, catch composition and landing port locations. For the first four sets of features we rely on statistical analysis to test the significance of potential differences, defining a dummy variable accounting for when a vessel derives more than half of its gross revenues from the closed waters 
and performing two-sample t-tests and linear regressions. For the last two features - catch composition and landing port locations - we map species bundles and trips' schedules at the vessel level.

\section{Second-order impacts}

\section{Discrete choice model of fishing relocation decisions}

In order to predict the reallocation of fishing effort that would result from the spatial closure, we estimate a DCM of fishing locations ${ }^{3}$. We build on a random utility model framework where fishers are assumed to be able to assign utility values to each of the fishing alternatives they face and choose the alternative yielding the highest utility (McFadden, 1974; Smith, 2010).

The model we estimate assumes that - conditional on being actively fishing and conditional on a given level of fishing effort and on a given location - fishers make a unique daily decision on where to fish according to a simple utility criterion that weighs traveling costs and expected rewards from a fishing site $j$ :

$$
\begin{gathered}
\mathrm{U}_{\mathrm{ijt}}=\beta_{\text {dist }} * \text { Dist }_{\mathrm{ijt}}+\beta_{\mathrm{VPUE}} * \mathrm{E}\left[\mathrm{VPUE}_{\mathrm{ijt}}\right]+\beta_{\mathrm{Nb.vs.oth.ft}} * \text { Nb.vs.other.ft } \\
+\beta_{\text {Act.own }-1}+\beta_{\text {Nb.vs.same.ft }} * \text { Act.own } \\
\text { ijt-1 } \\
+\varepsilon_{\mathrm{ijt}}(\text { Eq. 1) }
\end{gathered}
$$

where $\mathrm{i}$ is the vessel, $j$ is the site, $t$ is the day, and $\beta_{\text {dist }}, \beta_{\mathrm{VPUE}}, \beta_{\mathrm{Nb} . v s . o t h . f t}, \beta_{\mathrm{Nb} . v s . s a m e . f t}$ and $\beta_{\text {Act.own }}$ denote the marginal utilities of, respectively, the distance to a given location, Dist ${ }_{i j t}$, the associated expected value per unit of effort $\left(E\left[V_{P U E}\right]\right.$, the number of other vessels from the other fleet segments in site $j$ the day before, the number of other vessels of the same fleet segment in site $j$ the day before; and vessel's own fishing effort in site $j$ the day before. $\varepsilon_{\mathrm{ijt}}$ is a random utility shock. 
Following the results in the prior literature on DCMs (Smith et al., 2009), our model specification assumes that travel costs and expected revenues are the main predictors of the choice of the fishing location (Girardin et al., 2016). A commonly used proxy for travel costs is the distance to the fishing sites, usually reduced for computational purposes to the distance between the centroids of the alternative locations and the centroid of the current location (Abbott and Wilen, 2011; Haynie and Layton, 2010). Intuitively, this variable captures that further fishing sites incur not only higher fuel costs, but also require more time to be reached ${ }^{4}$.

With respect to fishers' expectations about revenues from a fishing site, we follow the literature that utilizes records of past performances for each site, aggregated at the fleet level (see, e.g., (Girardin et al., 2015; Smith, 2005)). Specifically, we assume that fishers consider both short and long-term information as well as both individual and fleet-level information, and weight information signals differently depending on which information is available or not (Abbott and Wilen, 2011; Hutniczak and Münch, 2018). Section C of the Appendix provides more details on how expected revenue is estimated, which model's specifications were considered, and how the model was selected.

The behaviors of other fishers along with fishers' past fishing patterns having been shown to influence fishers' decision-making (Girardin et al., 2016; Huang and Smith, 2014; Poos and Rijnsdorp, 2007), we account for those aspects by including the lagged level of other fishers' activity - in terms of number of vessels - in a given alternative (Nb.vs.other. $\mathrm{ft}_{\mathrm{ijt}-1}$ and Nb.vs.same.ft $\mathrm{ft}_{\mathrm{ijt}-1}$ ), as well as fishers' own level of fishing activity - in terms of number of fishing hours - in a given site the day before $\left(\right.$ Act.own $\left._{\mathrm{ijt}-1}\right){ }^{5}$ 
The choice of the spatial resolution of analysis must be carefully examined in the context of a discrete-choice framework. Numerous studies have shown that an ill-specified spatial choice set may bias parameter estimates and substantially impair the reliability of model results (Depalle et al., under review; Haab and Hicks, 1999; Jones et al., 2015; Manski, 1977; Parsons and Hauber, 1998).

For instance, Hicks and Schnier (2010) showed that welfare estimates are increased when accounting for endogenous consideration sets ("macro-regions") and using a two-stage decisionmaking framework. However, their study focused only a single-species fishery, for Atka mackerel. In line with this, latent class models have been commonly used in the recreation literature to account for heterogeneous choice sets resulting from decision-makers considering different sets of options (von Haefen, 2008). Nevertheless their application to spatial choices makes them prone to the dimensionality curse and leaves open the issue of defining the consideration sets. Explicitly accounting for observable heterogeneous characteristics of fishing vessels, Zhang and Smith (2011) investigated how a spatial closure - a marine reserve in this case - had different impacts across fishers. Yet, limited by the resolution of their dataset, they could not explore how such heterogeneity impacted the choice of the spatial definition of the choice set.

Data permitting, the choice of the model's spatial resolution (i.e., the size of the fishing sites in our case) must be considered alongside the temporal resolution at which decisions are made, the spatial extent of mobility patterns for the individual decision-maker, as well as the questions being investigated. In a study focusing on the spatial reallocation of fishing effort, a finer spatial resolution should allow a more refined analysis of potential reallocation patterns. However, we are also constrained in our choice of spatial resolution by the temporal scale of the 
dataset (daily aggregation). As a consequence, fishing sites must be defined with a spatial extent corresponding to the area that a vessel is likely to cover over a day of fishing. Analysis of the dataset shows that the specific spatial extent varies across vessels but tends to be more homogeneous within a fleet segment (Table 1$)^{6}$. It is thus likely that the resolution at which choices are defined for different fleet segments will vary, and that this should be accounted for in the estimation of the model.

We follow the methodology established by Depalle et al. (under review) to test the sensitivity of our model to different spatial resolutions of the alternatives, for the different fleet segments. Across the different spatial resolutions, we evaluate the reliability of the estimated models for predicting new choices of fishing locations, for each fleet segments. As an additional robustness check, we partition the data intro a training dataset and a test dataset to perform outof-sample predictions. We then compute the percentage of wrong predictions for each estimated model and use this information to select our preferred specification to predict the reallocation of fishing effort for each of the fleet segments. We also make predictions with the non-preferred spatial specifications to show the extent of the bias that would arise by assuming a homogeneous fleet and considering only a single spatial resolution of analysis.

A powerful feature of discrete-choice models based on a random utility framework is that, in addition to predicting new choices, they can be used to undertake a welfare analysis. In our case, the closure of UK waters to French fishers amounts to a restriction of their choice set which may prevent them from selecting their most preferred fishing location ${ }^{7}$, thereby incurring a welfare loss. We compute the welfare loss for a vessel facing a set of possible fishing sites as the utility difference (normalized by the marginal utility of distance) between the chosen site 
without the spatial restriction and the chosen site restricting the choice set to sites that lie outside the exclusion $\operatorname{area}^{8}$.

\section{Case study}

We consider a hypothetical case study simulating the closure of the UK EEZ to a subset of the French commercial fishing fleet, as could occur following the exit of the UK from the European Union ${ }^{9}$ (see Figure 1). Data was extracted from the SACROIS database developed by the French Research Institute for Exploitation of the Sea (Ifremer) under the supervision of the French Directorate for Marine Fisheries and Aquaculture (DPMA). The SACROIS database combines and reconciles French Vessel Monitoring System (VMS), logbooks and sales data from different sources (“SACROIS," 2017, see section A of the Appendix for further details).

We estimated the DCM described above on five key fleet segments - large exclusive bottom trawlers (BTR exc $>=18 \mathrm{~m}$ ), large dominant bottom trawlers (BTR dom $>=18 \mathrm{~m}$ ), vessels using traps $($ TRP $>=12 \mathrm{~m})$, netters $(\mathrm{DFN}>=12 \mathrm{~m})$, and dredgers $(\mathrm{DRD}>=12 \mathrm{~m})$, and we explore three levels of spatial aggregation for the size of the fishing sites. Table 2 summarizes the main characteristics of the fleet segments retained in the analysis. To make their daily decisions, we assumed fishers consider either: (1) $2^{\circ} \times 2^{\circ}$ squares; (2) $1^{\circ} \times 1 / 2^{\circ}$ squares (as defined by the ICES for its statistical analyses); or, (3) $1 / 2^{\circ} \times 1 / 2^{\circ}$ squares. We trained the model on 2013 and 2014 data and we used 2015 data for the test dataset. 


\section{Results}

\section{First-order impacts: economic importance of UK waters for the selected fleet}

\section{segments}

Ranking fleet segments by the share of landings originating from UK waters, the top three segments - bottom trawlers, exclusive or dominant, and vessels using traps - derived more than a third of their catches from UK waters. The levels of dependency drop to $15 \%$ and $10 \%$ for the next four segments and remain below $5 \%$ for the other segments. Dominant and exclusive bottom trawlers accounted for more than one fourth of vessels and one third of landings from our subset of fleets. In contrast, vessels using pots and traps - even though highly dependent on UK waters - only accounted for about $3 \%$ of the landings from the same subset.

When assessing the extent to which vessels depending highly on UK waters compared with the rest of the fleet, we did not find any significant differences ${ }^{10}$ regarding their technical characteristics (power and length), trips characteristics (average landing, landing's value or fishing effort), and fishing efficiency (average CPUE or VPUE). We also did not find that the exploitation of fishing grounds located in UK waters focused on a specific bundle of species: vessels from a same fleet segment caught the same sets of species in and outside the UK waters. Similarly, we did not find specific patterns of landing locations related to exploiting UK waters. The vast majority of vessels from the segments under study that fished in UK waters left and landed their catches in France, and more generally the majority of vessels left and landed their catch in the same port.

Finally, we assessed whether vessels fishing mainly in UK waters received different landing prices. Differences could stem, for example, from a premium on catches from this region 
(e.g., because the quality or the size of the fishes would be different), a greater ability of fishers to target higher valued fishes, or from some specificities in fishers' network of fishmongers. A statistical analysis of the imputed landing prices of twelve main species between 2012 and 2015 revealed that fishing in UK waters did not lead to fishers extracting higher landing prices. This finding implies, all else equal - in particular catch rates and other market prices - that the loss of access to UK waters for the segments under study would likely not result in lower prices for their catch.

Given these results, our use of the same métier structure to examine fishing choices before and after a hypothetical closure to the selected fishing fleets seems as an appropriate assumption.

\section{Second-order impacts: fishing effort reallocation and welfare impact}

We first present the results regarding the model estimates given the choice of spatial resolution for the alternatives. We then look at the model predictions regarding effort reallocation and welfare impacts of the closure scenarios on the selected fleets. Finally, we present the extent of estimates biases when not accounting for fleet heterogeneity.

\section{Model's estimates given the spatial resolution of the choice set}

Examination of the model's goodness of fit and prediction performance across the five fleet segments and the three spatial resolutions validates our approach in estimating segmentspecific models using varying spatial resolutions for the choice sets. Indeed, as shown in Table 3 our model of daily decisions performs poorly at high spatial resolutions for the most mobile fleet segments - exclusive and dominant large bottom trawlers, whose daily fishing activities span larger areas than those covered by the less mobile segments. Thus, reducing the choice of fishing location to a single $1^{\circ} \times 1 / 2^{\circ}$ (ICES rectangle) or $1 / 2^{\circ} \times 1 / 2^{\circ}$ rectangle per day appears to be 
inappropriate for these former segments ${ }^{11}$. Yet, it is an assumption that is commonly made by researchers estimating spatial choice models in a similar setting, who tend to use the ICES statistical grid as the default and unique spatial resolution of analysis (Batsleer et al., 2013; Poos and Rijnsdorp, 2007; Rijnsdorp et al., 2011; Simons et al., 2015).

In addition, even though data might allow the use of fine spatial resolutions, the levels of prediction errors for out-of-sample observations indicate that the spatial analysis should not be carried out at resolutions finer than $2^{\circ} \times 2^{\circ}$ for the bottom trawlers and $1^{\circ} \times 1 / 2^{\circ}$ for the netters, dredgers, and for the vessels using traps. Based on these results, we retain the following different spatial resolutions for each fleet segment: $2^{\circ} \times 2^{\circ}$ squares for the two segments of bottom trawlers and ICES squares for the other.

Considering only those selected resolutions, our simple model fits the data rather well, with pseudo- $\mathrm{R}^{2}$ ranging from 0.63 to 0.81 , and is able to predict out-of-sample observations with an error rate between $20 \%$ and $31 \%{ }^{12}$.

Table 4 illustrates the parameter estimates. Consistent with the prior literature, we find that the distance variable is significant statistically and negative. We also find that the variables accounting for the level of past activity of other vessels in a site are significant and positive for vessels from other fleet segments but significant and negative for vessels of the same fleet segment. The latter effect is commonly attributed to congestion and competition but the former effect is often not addressed given the scope of prior studies. Interestingly, other activity appears to attract vessels and mechanisms for this could be due in part to "safety in numbers" and the oceanographic characteristics of the sites. 
The discrete-choice literature has reported various effects regarding the effect of other fishers (Girardin et al., 2016). Girardin (2015) for instance found that the contemporaneous presence of other French vessels in a given site in the English Channel often had a significant negative effect on the choice of a fishing location. However, they also found that the presence of English vessels had a positive effect, which they explain by the fact that some French and English fleet segments targets scallops, a relatively sedentary species. Similarly, Russo et al. (2015) reported an attractive effect on the location choice of pair trawlers from fishing units but a repulsion effect from vessels that are not fishing, which would signal the absence of resources ${ }^{13}$.

Vessels' own activity the day before is found to be positively significant across all of the models. This means that vessels are more likely to stay fishing in the same ground rather than to move to exploit another fishing site. This finding is in line with the general result in the literature which usually reports - though over sometimes different time-windows - a significant positive effect of past fishing patterns (Abbott and Wilen, 2011; Girardin et al., 2016, 2015; Hynes et al., 2016).

As for the different components of the expected revenues from a site, a higher fleetaverage productivity of a site the past 30 days is found to be positively significant for exclusive bottom trawlers and netters, and not significant for other fleet segments.

When considering the impacts of past productivity on current location choices, the expectation is that fleet segments might weight past information in different ways due to the ephemeral characteristics of information in their respective fisheries. For example, we find that productivity of a site at the same point in time in the last season is statistically significant for dominant bottom trawlers, netters and dredgers with a positive effect when considering fleet- 
based historical average, whereas it is found to be statistically significant and negative for exclusive bottom trawlers, netters and dredgers when considering vessel-specific historical average. We also find across all fleet segments that vessel-specific past short-term average productivity is not statistically significant. When considering fleet-based short-term historical average, a significant positive effect is found for exclusive bottom trawlers and netters only.

A combination of a positive effect of short-term public information with a negative or non-significant effect of long-term private information appears consistent for vessels targeting highly mobile species with changing seasonal spatial pattern. In these cases, the value of information likely deprecates quickly implying that vessels are likely better off basing their expectations on a larger pool of information sources or on tracking technologies equipping the majority of vessels in the segment.

Overall, we find differentiated effects across the five fleet segments and across the four types of information. This supports our approach of estimating segment-specific models and considering different types of information for vessels having fundamentally different fishing strategies (see Section B in the Appendix for the estimated parameters at each spatial resolution as well as for a more detailed interpretation of the estimates).

\section{Effort reallocation and welfare impact predictions}

By using a daily temporal framework for the fishing decisions, our model provides a snapshot of where fishers would go given the set of fishing sites available at a given time of the year. Holding the distribution of choice occasions and of the associated levels of fishing effort fixed, we produce an estimate of the short-term reallocation of fishing effort for any given day of an observed fishing season. In order to have a representative picture of the new spatial distribution of fishing effort, we choose to estimate effort reallocation for each choice occasion 
observed in 2015 and to average fishing efforts over the year. Our approach is less susceptible to having a specific day of the year given undue weight in these calculations.

Figure 2 shows the predicted change - in terms of mean fishing hours per day - of the fishing pressure of each of the five key fleet segments in response to the hypothetical closure of the UK EEZ, using models estimated at the relevant spatial resolution for each fleet. Not surprisingly the sites that are the closest to the initial fishing grounds of French vessels in UK waters are those that are predicted to face the highest increases in fishing effort. For bottom trawlers, this involves an increase in fishing effort in the west of Brittany and in the Channel, as well as in the northern part of the Celtic Sea, south of the Irish shores. For vessels using traps, there is mainly one cluster of increased fishing pressure, north of Brittany. Netters are also predicted to relocate their fishing effort in this area as well as in the area north of the west end of the UK EEZ. Dredgers are predicted to increase their fishing pressure north of Normandy, in the eastern part of the Channel (see Figures D.1 to D.5 in the appendix).

According to our estimation, exclusive bottom trawlers and vessels using pots and traps are the most impacted, due in particular to the large welfare losses incurred by the loss of access to the fishing areas surrounding Cornwall (see Figure 2 top right panel). When excluding those sites, the magnitude of the mean utility loss of those two fleet segments becomes similar to the magnitude of the losses of the other fleet segments. Overall, the level of welfare losses of each fleet reflects their level of dependency to the closed areas. Dominant bottom trawlers show larger levels of impact than those for dredgers and netters (which derive less catches from the closed areas). Such a pattern of correllation is consistent with the assumption of utility maximization of our model: the more attractive a site, the more likely it is to be visited by vessels. 
The magnitude of the welfare losses and changes in the fishing effort intensifications we predict needs, however, to be qualified. Indeed, choosing a simplistic model for the sake of clarity, the predictions we present here do not take into account the dynamic nature of the behavior of fishers, which are likely to smooth the reallocation of their fishing effort through space and time. We attempted to assess the implications of such dynamic behavior by updating the day-to-day predictions of the model $^{14}$. Chaining predictions over the first 30 days of 2015 (the process is computationally demanding and the updating assumptions become weaker as the time span expands) we obtained welfare losses that are noticeably smaller for exclusive bottom trawlers and vessels using pots and traps (about $80 \%$ smaller), moderately smaller for dominant bottom trawlers and netters (about 20\% smaller), and noticeably larger for dredgers (about 300\% larger) than the welfare losses that would be estimated without chaining the predictions (cf. Figure E.5 in the appendix).

Similarly, we also do not model for the timing of the decisions to go on a fishing trip. Neither does our model account for the heterogeneity of choices within a fishing trip. As suggested in the literature by Sun et al. (2016) and Kuriyama et al. (2019) for instance, fishers may be, for example, more likely to choose fishing sites further away for the first day of a trip. We investigated the first day of trip effects and found, as in previous studies, that those effects are significant (see Section E of the Appendix for results). We leave this question as an interesting area for future research, as the quantitative exploration of the impacts of these effects on the analysis is beyond the scope of the present study.

Accounting for this nuance in the choice of the fishing location of the first days of trips can have mixed implications for the re-allocation of effort that is predicted by the model. On one side, sites that are located close to the French shores may be predicted to be less likely chosen, 
thereby alleviating part of the fishing intensification in the Channel for instance. However, on the other side it may also lead sites located near the south west end of the UK EEZ to be predicted to be more likely chosen, thereby increasing the fishing pressure in this area.

A key consideration in the analysis of impacts of closures is calibrating the spatial choice set with the decision-making process and scale of the closures. Any potential bias in the impact measures is also likely specific to fleet heterogeneity. For example, considering the same spatial scale with a fleet which includes vessels forming their decisions over largely different spatial ranges can lead to overestimate the impact for some and underestimate the impact for others, with an uncertain aggregate effect.Figure 3 shows the deviation of the predicted relative change in the total fishing effort of the five fleet segments when the same spatial resolution is used for the choice sets of all segments (results are aggregated at the coarser spatial resolution considered to allow comparisons, disagregated results for each spatial resolution are available in Section $\mathrm{C}$ of the Appendix).

Using only the coarsest resolution in model estimation leads to predicted relative changes that are relatively close to the predicted changes with specific choice set resolutions for each segment. The largest discrepancies in the predictions, neglecting marginally exploited areas, are the predicted increases in the fishing effort located at the edge of the UK EEZ, south of the Celtic sea $(+216 \%$ vs $+228 \%$ increased effort pressure), and north of Brittany $(+171 \%$ vs. $+161 \%)$. Carrying out the analysis using ICES spatial resolution $\left(1^{\circ} \times 1 / 2^{\circ}\right.$ rectangles $)$ produces results that differ more noticeably across the fleet segments. The increases in the fishing effort south of Ireland and north of Brittany are substantially overestimated with deviations of, respectively, $+17 \%$ and $+30 \%$, and compensated by lower predicted increases in the Celtic Sea close to the UK EEZ (- 33\%) and further West (-50\%). Figure 4 shows the estimated welfare 
losses when using the same spatial resolution for all fleet segments, expressed in terms of $\%$ deviation from the estimates presented in Figure 2. Losses are generally estimated to be less important as the spatial resolution chosen gets finer. This is likely due to the large weight given to the distance factor relative to other factors in our model, combined with the mechanical reduction of the differences in distance characteristics between two options, when considering finer scales.

\section{Discussion and Conclusion}

Large-scale spatial closures are increasingly considered as part of the marine policy toolbox. At the same time, there have been growing efforts to develop approaches that help assess the impacts of such closures on marine fisheries, beyond the first-order consequences associated with the loss of access to certain areas, and including the cascading effects due to the reallocation of fishing effort. We propose a methodology to assess such impacts while accounting for the diversity of fishing strategies among fishing fleets. Using a hypothetical scenario regarding the exclusion of selected French fleet segments from the UK exclusive economic zone, we first provide a thorough analysis of the current economic dependencies of these fleet segments to UK fishing grounds. While this produces a first-order assessment of the magnitude of the economic stakes and of where future points of friction may arise, on which stakeholders are likely to focus when examining alternative spatial management scenarios, it does not provide an actual assessment of the total effects resulting from the reallocation of fishing effort because it misses the adaptation of the fleets.

We then model the immediate reallocation of fishing effort in the areas remaining accessible, which would be the most obvious response of fishers to an area closure in the short- 
term. Supported by our finding that the bundle of species caught by vessels exploiting fishing grounds in UK waters is not different from the bundle of species of other vessels, we assume that fishers would still be able to target the same set of species as in UK waters. Focusing on five main fleet segments, we provide a snapshot of the average short-term reallocation of fishing effort. This points to three critical hotspots of potentially increased fishing pressure: the western and eastern parts of the Channel close to the French coast, as well as the northern part of the Celtic Sea, south of the Irish shores. An intensification of the fishing activities in these areas is likely to increase the potential for conflicts of use of resources and of the maritime domain.

Our results also show that the ability to account for this diversity increases the reliability and the accuracy of impact assessments. The approach illustrates the value of fine-resolution spatial data to analyze fishing activities and to assess the robustness of predictions regarding the response of fishers to changes in their fishing opportunities by testing different spatial scales. If we could not tailor the spatial resolution of choice sets to specific fleet segments, our results show that an impact assessment could be misleading. For example, we find that, provided our identification of more relevant resolution is correct, using the resolution of the ICES rectangles when modeling choices of all vessels would over-predict reallocation of effort towards regions close to the south shores of Ireland, and under-predict effort reallocation towards regions closer to the delineation line of the UK EEZ.

Regarding welfare impacts on the fleets, we find that using a finer resolution for the choice sets when coarser resolutions may be more relevant (as suggested by better prediction performances for instance) leads to an under-estimate of the losses. At the same time, we also show that model predictions may be highly unreliable with such resolution. Given that we find that the probabilities of choosing a site are mostly determined by how far sites are from a vessel 
location (recall the larger estimated coefficients for the distance variable), this may not be surprising as the gap in the distance to alternative site options gets larger as the spatial resolution gets coarser. However, this result does not apply for dredgers and netters at the finest spatial resolution. This may be explained by the specific spatial configurations of the sites and of the closure area in the Channel. Indeed, all the spatial resolutions we considered in this region are still rather coarse relatively to the eastern part of the Channel $^{15}$, the region where netters and dredgers operate and would relocate their fishing effort. Thus, depending on the spatial configuration of the statistical squares in the region, the attractiveness of the sites located outside the closed area may be extremeley heterogenous. Should the spatial resolution allow for a finer description of the area, distance or productiviy differentials may be more homogeneously distributed between sites.

The relocation that we predict of the large bottom trawlers closer to French coastal fishing grounds would have the potential to trigger important domino effects on the coastal fleet segments in the region, as well as on coastal ecosystems. Examining the full consequences of the same number of vessels fishing in a smaller area would also require information on a number of other uses of marine space. Indeed, areas such as the Channel, are already experiencing intense competition for space between maritime activities (Girardin, 2015; Halpern et al., 2008). Moreover, even though our study focuses on French fleet segments, a number of other European vessels also exploit UK waters. For example, Belgian and Dutch vessels have been reported to fish side by side with French vessels in the eastern part of the English Channel (Girardin, 2015), while the Celtic Sea is known to be an economically important fishing site for Irish, Belgian and Spanish fishers (Mateo et al., 2016). Interactions with smaller vessels, not accounted for in our study, should also be considered. 
The reallocation of fishing effort can also have consequences downstream, across the fishery value chain from the ports of landing to the consumers. In this regard - and leaving aside issues related to market access - how a new distribution of fishing effort and a new distribution of catches would translate into new landings' locations and new market dynamics is a central matter. Changes in fishers' level of activity in one place can have important impacts on the local fishing communities, notably in the processing sector that may be confronted to over- or undercapacity issues. This may in turn impact fishers, who may face changing landing prices and may have to establish new networks of wholesale fishmongers.

Finally, the impact of the spatial reallocation of fishing effort on the dynamics of the biological stocks should also be taken into account, as this would entail changes in the catch rates and revenues per unit of effort associated to different métiers applied to different areas. While the state and the dynamics of some of the most important fish stocks are now generally well-understood and regularly monitored, the understanding of their spatial distribution at fine scales is not as strong, and many of the species contributing to the economic returns of the fleets remain poorly known. This makes the anticipation of the impact of changes in the intensity and spatial distribution of fishing pressure by the fleets even more uncertain.

Accounting for the full suite of these dynamic effects is a complex task that would require the development of a complete bio-economic model of the different fleets and their interactions with the fish stocks, as well as the European fish supply chain.

\section{Acknowledgments}

We gratefully acknowledge the French DPMA who provided access to anonymized VMS and logbook data and the team of the SIH (French fisheries information system) who processed 
it. Special thanks go to Jérôme Weill and Patrick Berthou who provided precious support through their expertise of the dataset and of the empirical setting. All data used were aggregated in such a way that the confidentiality of vessels was not compromised. The statements, findings, conclusions and recommendations are those of the authors and do not necessarily reflect the views of the French DPMA.

This work was also supported by the "Laboratoire d'Excellence" LabexMER (ANR-10LABX-19) and co-funded by a grant from the French government under the program "Investissements d'Avenir".

\section{References}

Abbott, J.K., Wilen, J.E., 2011. Dissecting the tragedy: A spatial model of behavior in the commons. J. Environ. Econ. Manag. 62, 386-401. https://doi.org/10.1016/j.jeem.2011.07.001

Batsleer, J., Poos, J., Marchal, P., Vermard, Y., Rijnsdorp, A., 2013. Mixed fisheries management: protecting the weakest link. Mar. Ecol. Prog. Ser. 479, 177-190. https://doi.org/10.3354/meps 10203

Branch, T.A., Hilborn, R., Haynie, A.C., Fay, G., Flynn, L., Griffiths, J., Marshall, K.N., Randall, J.K., Scheuerell, J.M., Ward, E.J., Young, M., 2006. Fleet dynamics and fishermen behavior: lessons for fisheries managers. Can. J. Fish. Aquat. Sci. 63, 16471668. https://doi.org/10.1139/f06-072

Collie, J.S., (Vic) Adamowicz, W.L., Beck, M.W., Craig, B., Essington, T.E., Fluharty, D., Rice, J., Sanchirico, J.N., 2013. Marine spatial planning in practice. Estuar. Coast. Shelf Sci. 117, 1-11. https://doi.org/10.1016/j.ecss.2012.11.010

Depalle, M., 2018. Geospatial Data and Fishery Management: Innovative Modelling Approaches. University of California, Davis, Davis.

Depalle, M., Sanchirico, J.N., Haynie, A.C., Thébaud, O., O’Farrell, S., Perruso, L., under review. Scale-dependency in discrete choice models: a fishery application (Working paper). UC Davis.

Fuller, E.C., Samhouri, J.F., Stoll, J.S., Levin, S.A., Watson, J.R., Handling editor: Robert Blasiak, 2017. Characterizing fisheries connectivity in marine social-ecological systems. ICES J. Mar. Sci. 74, 2087-2096. https://doi.org/10.1093/icesjms/fsx128

Fulton, E.A., Smith, A.D.M., Smith, D.C., van Putten, I.E., 2011. Human behaviour: the key source of uncertainty in fisheries management: Human behaviour and fisheries management. Fish Fish. 12, 2-17. https://doi.org/10.1111/j.1467-2979.2010.00371.x 
Girardin, R., 2015. Ecosystem and fishers' behaviour modelling : two crucial and interacting approaches to support ecosystem based fisheries management in the eastern english channel (Thèse de doctorat). Université Lille 1.

Girardin, R., Hamon, K.G., Pinnegar, J., Poos, J.J., Thébaud, O., Tidd, A., Vermard, Y., Marchal, P., 2016. Thirty years of fleet dynamics modelling using discrete-choice models: What have we learned? Fish Fish. https://doi.org/10.1111/faf.12194

Girardin, R., Vermard, Y., Thébaud, O., Tidd, A., Marchal, P., 2015. Predicting fisher response to competition for space and resources in a mixed demersal fishery. Ocean Coast. Manag. 106, 124-135. https://doi.org/10.1016/j.ocecoaman.2015.01.017

Haab, T.C., Hicks, R.L., 1999. Choice set considerations in models of recreation demand: History and current state of the art. Mar. Resour. Econ. 14, 271-281.

Halpern, B.S., Walbridge, S., Selkoe, K.A., Kappel, C.V., Micheli, F., D’Agrosa, C., Bruno, J.F., Casey, K.S., Ebert, C., Fox, H.E., Fujita, R., Heinemann, D., Lenihan, H.S., Madin, E.M.P., Perry, M.T., Selig, E.R., Spalding, M., Steneck, R., Watson, R., 2008. A Global Map of Human Impact on Marine Ecosystems. Science 319, 948-952. https://doi.org/10.1126/science.1149345

Haynie, A.C., Layton, F.D., 2010. An expected profit model for monetizing fishing location choices. J. Environ. Econ. Manag. 59, 165-176. https://doi.org/10.1016/j.jeem.2009.11.001

Huang, A., Levinson, D., 2015. Axis of travel: Modeling non-work destination choice with GPS data. Transp. Res. Part C Emerg. Technol. 58, 208-223. https://doi.org/10.1016/j.trc.2015.03.022

Huang, L., Smith, M.D., 2014. The Dynamic Efficiency Costs of Common-Pool Resource Exploitation. Am. Econ. Rev. 104, 4071-4103. https://doi.org/10.1257/aer.104.12.4071

Hutniczak, B., Münch, A., 2018. Fishermen's location choice under spatio-temporal update of expectations. J. Choice Model. 28, 124-136. https://doi.org/10.1016/j.jocm.2018.05.002

Hynes, S., Gerritsen, H., Breen, B., Johnson, M., 2016. Discrete choice modelling of fisheries with nuanced spatial information. Mar. Policy 72, 156-165. https://doi.org/10.1016/j.marpol.2016.07.004

Jones, J., Thomas, I., Peeters, D., 2015. Forecasting jobs location choices by Discrete Choice Models: A sensitivity analysis to scale and implications for LUTI models. Region 2, 6793.

Jones, P.J.S., 2016. Marine spatial planning in reality_Introduction to case studies and discussion of findings. Mar. Policy 9.

Kuriyama, P.T., Holland, D.S., Barnett, L.A.K., Branch, T.A., Hicks, R.L., Schnier, K.E., 2019. Catch shares drive fleet consolidation and increased targeting but not spatial effort concentration nor changes in location choice in a multispecies trawl fishery. Can. J. Fish. Aquat. Sci. https://doi.org/10.1139/cjfas-2019-0005

Manski, C.F., 1977. The structure of random utility models. Theory Decis. 8, 229-254. https://doi.org/10.1007/BF00133443

Mateo, M., Pawlowski, L., Robert, M., 2016. Highly mixed fisheries: fine-scale spatial patterns in retained catches of French fisheries in the Celtic Sea. ICES J. Mar. Sci. J. Cons. fsw129. https://doi.org/10.1093/icesjms/fsw129

McFadden, D., 1974. Conditional Logit Analysis of Qualitative Choice Behaviour, in: Frontiers in Econometrics. Zarembka, New York. 
Parsons, G.R., Hauber, A.B., 1998. Spatial Boundaries and Choice Set Definition in a Random Utility Model of Recreation Demand. Land Econ. 74, 32. https://doi.org/10.2307/3147211

Poos, J.-J., Rijnsdorp, A.D., 2007. An “experiment” on effort allocation of fishing vessels: the role of interference competition and area specialization. Can. J. Fish. Aquat. Sci. 64, 304313. https://doi.org/10.1139/f06-177

Rijnsdorp, A.D., Poos, J.J., Quirijns, F.J., Grant, J., 2011. Spatial dimension and exploitation dynamics of local fishing grounds by fishers targeting several flatfish species. Can. J. Fish. Aquat. Sci. 68, 1064-1076. https://doi.org/10.1139/f2011-032

Russo, T., Pulcinella, J., Parisi, A., Martinelli, M., Belardinelli, A., Santojanni, A., Cataudella, S., Colella, S., Anderlini, L., 2015. Modelling the strategy of mid-water trawlers targeting small pelagic fish in the Adriatic Sea and its drivers. Ecol. Model. 300, 102-113. https://doi.org/10.1016/j.ecolmodel.2014.12.001

SACROIS [WWW Document], 2017. . Système Inf. Halieut. URL http://sih.ifremer.fr/Description-des-donnees/Donnees-estimees/SACROIS

Sanchirico, J.N., Eagle, J., Palumbi, S., Jr, B.H.T., 2010. Comprehensive Planning, DominantUse-Zones, and User Rights: a New Era in Ocean Governance. Bull. Mar. Sci. 86, 15.

Sanchirico, J.N., Wilen, J.E., 1999. Bioeconomics of Spatial Exploitation in a Patchy Environment. J. Environ. Econ. Manag. 37, 129-150. https://doi.org/10.1006/jeem.1998.1060

Scott, A., 1955. The fishery: the objectives of sole ownership. J. Polit. Econ. 116-124.

Sievanen, L., Leslie, H.M., Wondolleck, J.M., Yaffee, S.L., McLeod, K.L., Campbell, L.M., 2011. Linking topdown and bottomup processes through the new U.S. National Ocean Policy. Conserv. Lett. 6.

Simons, S.L., Doring, R., Temming, A., 2015. Modelling fishers' response to discard prevention strategies: the case of the North Sea saithe fishery. ICES J. Mar. Sci. 72, 1530-1544. https://doi.org/10.1093/icesjms/fsu229

Smith, M.D., 2010. Toward an econometric foundation for marine ecosystem-based management. Bull. Mar. Sci. 86, 461-477.

Smith, M.D., 2005. State dependence and heterogeneity in fishing location choice. J. Environ. Econ. Manag. 50, 319-340. https://doi.org/10.1016/j.jeem.2005.04.001

Smith, M.D., Sanchirico, J.N., Wilen, J.E., 2009. The economics of spatial-dynamic processes: Applications to renewable resources. J. Environ. Econ. Manag., Frontiers of Environmental and Resource Economics 57, 104-121. https://doi.org/10.1016/j.jeem.2008.08.001

Sun, J., Hinton, M. G., \& Webster, D. G. (2016). Modeling the spatial dynamics of international tuna fleets. PLoS ONE, 11(8). https://doi.org/10.1371/journal.pone.0159626

von Haefen, R.H., 2008. Latent Consideration Sets and Continuous Demand Systems. Environ. Resour. Econ. 41, 363-379. https://doi.org/10.1007/s10640-008-9196-X 
Figures and Tables

Table 1. Spatial extents of fishing activities for each fleet segment, in numbers of $1 / 20^{\circ} \times 1 / 20^{\circ}$ squares visited per day (2012-15 period).

\begin{tabular}{l|cccc}
\hline & \multicolumn{5}{c}{ Range $\left(1 / 20^{\circ} \times 1 / 20^{\circ}\right.$ squares $)$} \\
Fleet segments & Mean & S.d. & Min & Max \\
\hline Bottom Trawl exc. $\geq 18 \mathrm{~m}$ & 20 & 8 & 1 & 52 \\
Bottom Trawl dom. $\geq 18 \mathrm{~m}$ & 16 & 8 & 1 & 46 \\
Pots \& Traps $\geq 12 \mathrm{~m}$ & 9 & 4 & 1 & 26 \\
Drift \& Fixed Nets $\geq 12 \mathrm{~m}$ & 6 & 3 & 1 & 45 \\
Dredge $\geq 12 \mathrm{~m}$ & 7 & 5 & 1 & 44 \\
\hline
\end{tabular}




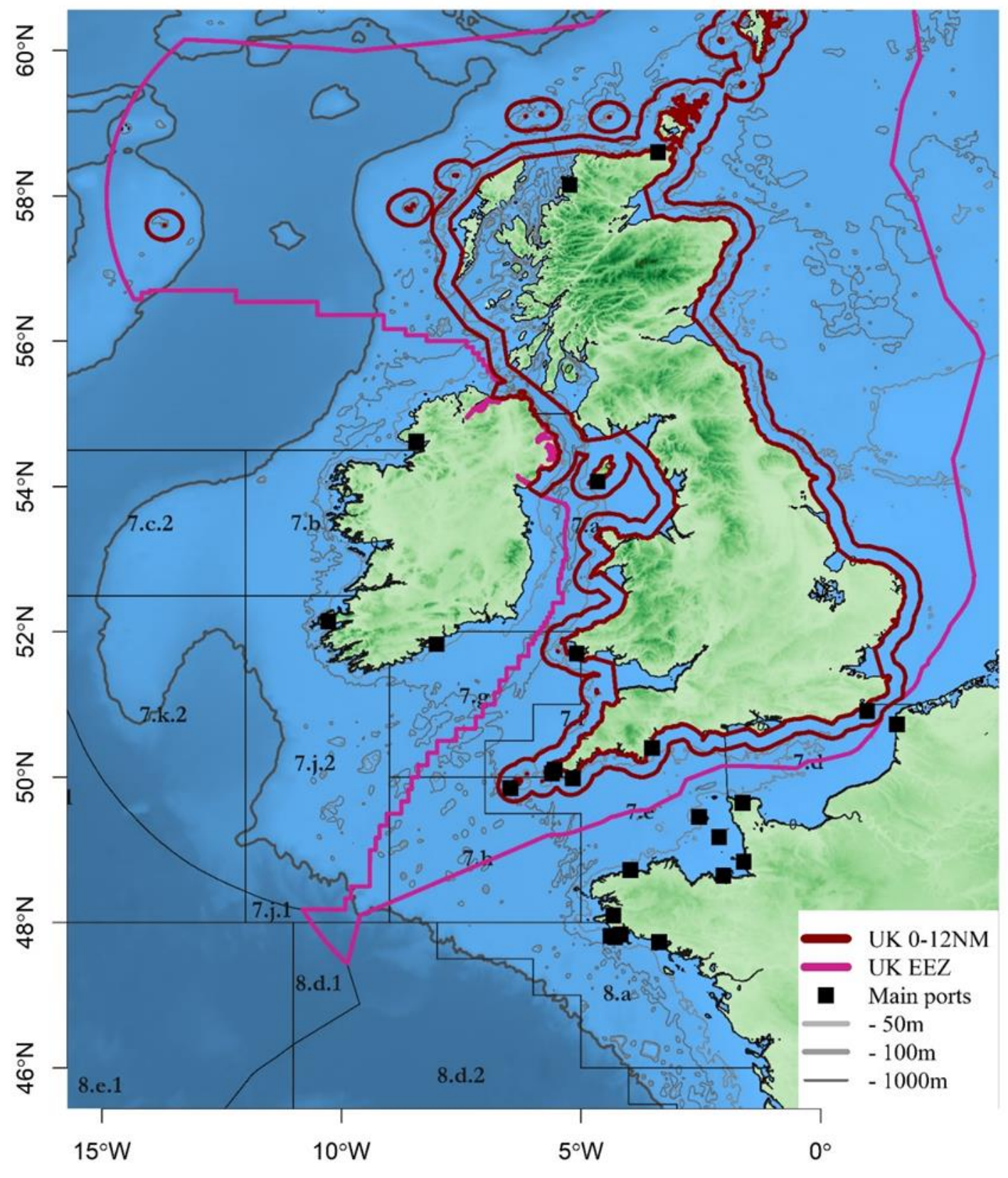

Figure 1. Maritime boundaries and main fishing ports in the North East Atlantic regions. ICES areas VII and VIII's delineations are shown in light grey. Source: authors production. Maritime boundaries are based on the Maritime Boundaries Geodatabase, version 10 from Flanders Marine Institute (2018) (available online at http://www.marineregions.org/). 
Table 2. Main characteristics of the selected fleet segments (statistics over the 2012-15

\begin{tabular}{|c|c|c|c|c|c|c|c|}
\hline \multirow[b]{2}{*}{ Fleet segments } & \multirow[t]{2}{*}{$\begin{array}{c}\# \\
\text { vessels }\end{array}$} & \multicolumn{2}{|c|}{$\begin{array}{l}\text { Length } \\
\text { (m) }\end{array}$} & \multicolumn{2}{|c|}{$\begin{array}{c}\text { Catch } \\
\text { (kg/day) }\end{array}$} & \multicolumn{2}{|c|}{$\begin{array}{c}\text { Trip duration } \\
\text { (day) }\end{array}$} \\
\hline & & Mean & S.d. & Mean & S.d. & Mean & S.d. \\
\hline Bottom Trawl exc. $\geq 18 \mathrm{~m}$ & 189 & 25.6 & 8.2 & 1,688 & 1,638 & 6.4 & 3.6 \\
\hline Bottom Trawl dom. $\geq 18 \mathrm{~m}$ & 71 & 24.2 & 5.0 & 1,879 & 3,283 & 3.4 & 3.0 \\
\hline Pots \& Traps $\geq 12 \mathrm{~m}$ & 19 & 19.7 & 4.5 & 1,307 & 2,013 & 2.4 & 3.2 \\
\hline Drift $\&$ Fixed Nets $\geq 12 \mathrm{~m}$ & 135 & 19.4 & 6.6 & 1,118 & 1,870 & 1.8 & 2.5 \\
\hline Dredge $\geq 12 \mathrm{~m}$ & 131 & 16.0 & 2.6 & 872 & 1,660 & 1.1 & 1.0 \\
\hline
\end{tabular}


Table 3. Summary statistics of the estimated models of fishing locations. Prediction errors were computed performing an out-of-sample prediction in 2015 from the trained model in 2013-14.

\begin{tabular}{|c|c|c|c|c|c|c|c|}
\hline \multirow[b]{2}{*}{ Fleet segments } & \multirow[t]{2}{*}{$\#$} & \multicolumn{3}{|c|}{$\begin{array}{c}\text { Goodness of fit } \\
\text { (pseudo-R }{ }^{2} \text { ) }\end{array}$} & \multicolumn{3}{|c|}{$\begin{array}{l}\text { Prediction errors } \\
\text { (\% wrong) }\end{array}$} \\
\hline & & $2^{\circ} \times 2^{\circ}$ & ICES & $1 / 2^{\circ} X^{1 / 2} 2^{\circ}$ & $2^{\circ} \times 2^{\circ}$ & ICES & $1 / 2^{\circ} x^{1 / 2^{0}}$ \\
\hline Bottom Trawl exc. $\geq 18 \mathrm{~m}$ & 28,475 & 0,71 & 0,626 & 0,59 & $30 \%$ & $49 \%$ & $57 \%$ \\
\hline Bottom Trawl dom. $\geq 18 \mathrm{~m}$ & 7,330 & 0,705 & 0,59 & 0,549 & $31 \%$ & $53 \%$ & $61 \%$ \\
\hline Pots \& Traps $\geq 12 \mathrm{~m}$ & 1,725 & 0,817 & 0,782 & 0,746 & $11 \%$ & $20 \%$ & $25 \%$ \\
\hline Drift \& Fixed Nets $\geq 12 \mathrm{~m}$ & 20,569 & 0,862 & 0,805 & 0,775 & $13 \%$ & $25 \%$ & $30 \%$ \\
\hline Dredge $\geq 12 \mathrm{~m}$ & 12,721 & 0,661 & 0,63 & 0,613 & $15 \%$ & $30 \%$ & $36 \%$ \\
\hline
\end{tabular}


Table 4. Average marginal effects of the explanatory variables of the discrete-choice model of fishing locations for an increase of 1 standard deviation. For each fleet segment the parameters shown are those obtained using the appropriate spatial resolution for defining fishing site options, i.e. $2^{\circ} \times 2^{\circ}$ squares for the two segments of bottom trawlers and ICES squares for the other. Significance levels: $0.1 \% * * *, 1 \% * *, 5 \% *, 10 \%$.

\begin{tabular}{|c|c|c|c|c|c|c|}
\hline & & $\begin{array}{l}\text { Bottom Trawl } \\
\text { exc. } \geq 18 \mathrm{~m}\end{array}$ & $\begin{array}{l}\text { Bottom Trawl } \\
\text { dom. } \geq 18 \mathrm{~m}\end{array}$ & $\begin{array}{l}\text { Pots \& Traps } \\
\geq 12 \mathrm{~m}\end{array}$ & $\begin{array}{l}\text { Drift \& Fixed } \\
\text { Nets } \geq 12 \mathrm{~m}\end{array}$ & $\begin{array}{l}\text { Dredge } \\
\geq 12 \mathrm{~m}\end{array}$ \\
\hline \multirow{4}{*}{\multicolumn{2}{|c|}{$\begin{array}{c}\text { Distance } \\
\text { N.vs.other.ft.d1 } \\
\text { N.vs.same.ft.d1 } \\
\text { Vessel's past fishing effort }\end{array}$}} & $-0.05 * * *$ & $-0.166 * * *$ & $-0.058 * * *$ & $-0.091 * * *$ & $-0.132 * * *$ \\
\hline & & $0.012 * * *$ & $0.031 * * *$ & $0.022 * * *$ & $0.009 * * *$ & $0.019 * * * *$ \\
\hline & & $-0.993 * * *$ & $-1.471 * * *$ & $-1.272 * * *$ & $-1.74 * * *$ & $-2.854 * * *$ \\
\hline & & $0.006 * * *$ & $0.011 * * *$ & $0.029 * * *$ & $0.004 * * *$ & $0.002 * * *$ \\
\hline \multirow{4}{*}{ 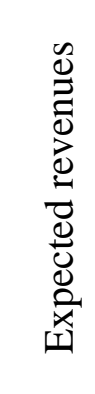 } & $\begin{array}{l}\text { Short-term - fleet } \\
\text { VPUE }\end{array}$ & $0.008 * * *$ & -0.001 & 0.012 & $0.008 * * *$ & -0.001 \\
\hline & $\begin{array}{l}\text { Short-term - ind. } \\
\text { VPUE }\end{array}$ & -0.003 . & 0.007 & -0.018 & -0.001 & -0.001 \\
\hline & $\begin{array}{l}\text { Long-term - fleet } \\
\text { VPUE }\end{array}$ & 0.001 & $0.02 *$ & -0.005 & $0.024 * * *$ & $0.013 * * * *$ \\
\hline & $\begin{array}{l}\text { Long-term - ind. } \\
\text { VPUE }\end{array}$ & $-0.006 * * *$ & 0.002 & -0.005 & $-0.007 *$ & $-0.011 *$ \\
\hline
\end{tabular}




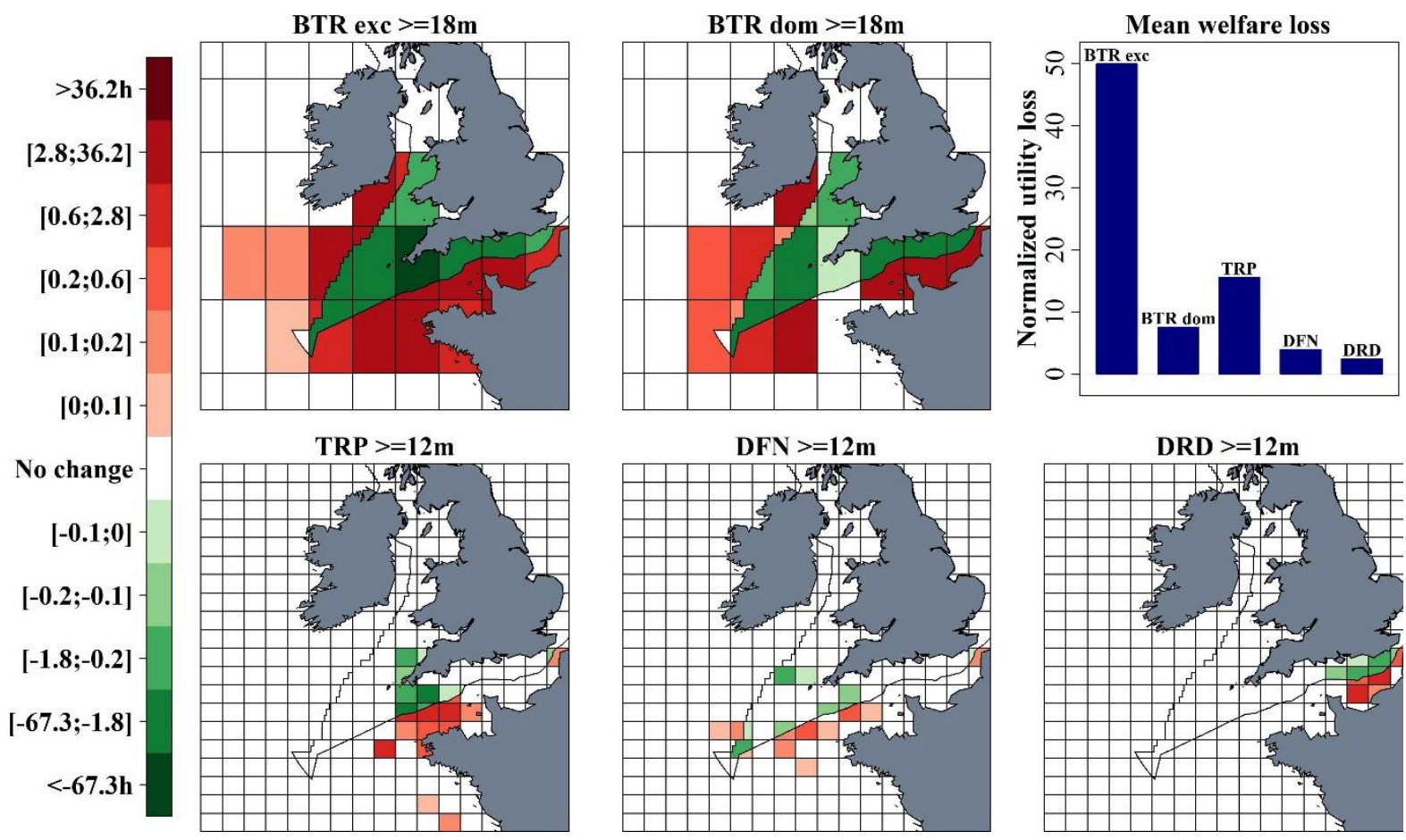

Figure 1 Predicted absolute changes in the mean daily fishing hours and in the mean

welfare loss of the five key fleet segments considered in response of the closure of the UK EEZ.

Welfare losses are computed at the choice occasion level and measured in terms of utility loss normalized with the marginal utility of distance. 
Figure 2 Deviation (in \% points) with the predicted relative changes in the total fishing hours of the five fleet segments when using one spatial resolution for all the segments. To allow comparisons, results are aggregated at the coarser spatial resolution considered $\left(2^{\circ} \times 2^{\circ}\right)$. A $x \%$ deviation shown in the figure means that, if the model estimated at the relevant spatial resolutions predicted a y $\%$ change in the total fishing pressure of the five fleet segments, using the same resolution for all the segments leads to $\mathrm{a}(\mathrm{x}+\mathrm{y}) \%$ predicted change. 


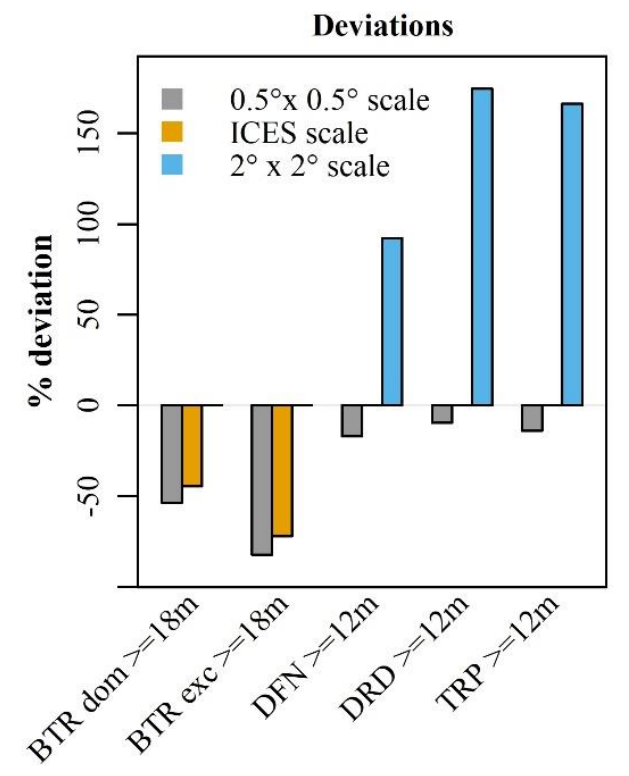

Figure 3 Deviation (relatively to the estimates presented in Figure 2) in the normalized mean welfare loss by choice occasion when using the same spatial resolution for all the fleet segments.

\footnotetext{
${ }^{1}$ DCMs can also be used to assess effort reallocation and ensuing distributional impacts of catch share policies (Kuriyama et al., 2019).

${ }^{2}$ We consider that as soon as a statistical square has some of its portion overlapping the closed area, all the catches and revenues allocated to this square belong to the closed area. Proceeding similarly using more spatially aggregated data (e.g., at the resolutions used for estimated the DCM) would have resulted in an increasing overestimation of the losses and smoothed out the levels of dependency to the closed area between the different fleet segments.

${ }^{3}$ Note that instead of using the model to assess where fishers would go if a large-scale closure was implemented, the model could be also used to build the counterfactual of where fishers would have gone if a large-scale closure had not been implemented. The underlying assumption would be that the drivers of choices for individual vessels considered have not changed and are still being adequately captured by the data used (i.e. in the absence of serious observation biases), between the before and after situations. In particular, this implies that the model would remain
} 
relevant probably only for relatively short-term impact assessments, given the complexity of determinants of fishing behavior in a diverse fishery system such as the one considered here.

${ }^{4}$ To take into account the additional cost of visiting a site located further away from the port of return - as in Hutniczak and Münch (2018) - we also included the distance of sites to the observed landing port. However, we did not find the model to yield significantly different results in most of cases and thus decided not to present it here.

${ }^{5}$ Specifically, we account for the fishing activity across all of the other fleet segments in our dataset, rather just focusing on the activity of the other vessels among the five selected fleet segments.

${ }^{6}$ For instance, in our dataset large bottom trawlers cover on average 20 ( \pm 8 s.d.) $1 / 20^{\circ} \times 1 / 20^{\circ}$ statistical squares within a single day whereas the average for vessels using traps or pots is only 9 ( \pm 4 s.d.).

${ }^{7}$ Preferred, not only in terms of higher expected profits, but also in terms of intrinsic preference for a particular site. However, in the specification of the model presented here we do not include vessel-specific site dummies that would capture this effect.

${ }^{8}$ Statistics regarding the distribution of welfare losses within a fleet segment were computed at the level of the choice occasion. Clustering first by vessels did not significantly change the results.

${ }^{9}$ Based on the EU Scientific, Technical and Economic Committee for Fisheries (STECF) data (2018), the French fishing fleet is one the main non-UK EU fleet to operate in UK waters, along with the Irish, Dutch, German and Danish fleets (see. Andersen et al., 2017 for a study of the possible impact of Brexit on the Danish fishing sector).

${ }^{10}$ Except in a few instances such as the average landing per trip of large dominant bottom trawlers or the average CPUE of large exclusive bottom trawler, that turned out not to be consistent from one year to another.

${ }^{11}$ It may seem surprising given that even a $1 / 2^{\circ} \times 1 / 2^{\circ}$ rectangle encompasses 100 of our « base $» \frac{1}{20} \circ \times \frac{1}{20}^{\circ}$ squares which is about twice the observed maximum of base squares covered by trawlers in a day in our dataset. However, most of the time, the observed disaggregated fishing locations of vessels are not confined to a single aggregated statistical rectangle and can actually span several, thereby inducing an approximation bias when reducing the number of visited rectangles to only one per day.

${ }^{12}$ Unfortunately, we cannot offer a theoretical basis to support the choice of a metrics over another, should there be conflicting conclusions regarding the adequate spatial resolution. However, as our welfare analysis is ex-ante and based on the estimation of a counterfactual - where fishers would go in the case of a large-scale closure -, it would 
make sense to favor a metrics accounting for the prediction performance of the model rather than on its ability to fit the data well.

13 In Russo et al., "units" designate pairs of vessels fishing by means of a pair trawl systems. The distinction between fishing and non-fishing units is made applying a speed filter: vessels having VMS points with a speed of between $3.5 \mathrm{~km} \cdot \mathrm{h}^{-1}$ and $4.5 \mathrm{~km} \cdot \mathrm{h}^{-1}$ are considered as units that are fishing.

14 To do so we needed to make an assumption regarding how the variables related to the productivity of vessels in each of the potentially selected sites were updated over time (see section E of the appendix for further details).

15 In the finest spatial scale the longitudinal size of the statistical squares is 30NM whereas the shortest distance between French and British shores is only 18NM. 


\section{Appendix}

\section{A. Analytics of the $\mathbf{1}^{\text {st }}$ and $2^{\text {nd }}$ order effects for the evaluation of the economic impact a spatial closure}

Equations A.1 and A.2 show the analytics of the 1st and 2nd order effects for the evaluation of the economic impact a spatial closure. We make explicit which variables are subjected to be modified by a change in the set of permitted fishing areas by using a tilde accent.

$$
\begin{aligned}
& \Delta^{1 s t}=\sum_{a}^{A} \sum_{g}^{G_{a}} \sum_{s}^{S_{g}} P_{a, g, s} * \sum_{i, j}^{(I \in g, J \in a)} C P U E_{i, j, s} * \text { Effort }_{i, j}-\sum_{a}^{A \backslash \Omega} \sum_{g}^{G_{a}} \sum_{s}^{S_{g}} P_{a, g, s} * \\
& \sum_{i, j}^{(I \in g, J \in a)} \operatorname{CPUE}_{i, j, s} * \text { Effort }_{i, j}(\text { Eq. A.1) } \\
& \Delta^{f u l l}=\sum_{a}^{A} \sum_{g}^{G_{a}} \sum_{s}^{S_{g}} P_{a, g, s} * \sum_{i, j}^{(I \in g, J \in a)} C P U E_{i, j, s} * \text { Effort }_{i, j}-\sum_{a}^{A \backslash \Omega} \sum_{g}^{\widetilde{G_{a}}} \widetilde{\sum_{s}^{\widetilde{S_{g}}}} \widetilde{P_{a, g, s}} * \\
& \sum_{i, j}^{(I \in g, J \in a)}{\widetilde{C P U E_{l, j, S}}}_{E E \widetilde{f o r}} t_{l, j} \text { (Eq. A.2) }
\end{aligned}
$$

where $\mathrm{i}$ is a vessel using a gear $g$, fishing species $s$ in $j$ sites located in permitted areas $a$. I is the set of vessels using a gear $g$, J is the set of sites located in the permitted area $a, S_{g}$ is the set of species captured by the gear $g, G_{a}$ is the set of gears used in area $a, A$ and $A \backslash \Omega$ are the set of permitted areas, respectively without and with the spatial restriction $\Omega . P_{a, g, s}$ is the landing price of the species $s$ fished in the area $a$ using the gear $g, C P U E_{i, j, s}$ is the catch per unit of effort and Effort $_{i, j}$ is the fishing effort. We omit the time subscript for the sake of clarity. 


\section{B. SACROIS Data}

The SACROIS Dataset we used focuses on vessels operating in the fishing areas VII and VIII as defined by the International Council for the Exploration of the Sea (ICES), over the period from 2001 to 2015 (Figure 1) and for which anonymized data was available. In addition to information about vessels' technical characteristics (e.g., length, power) and vessels' type of fishing activity (categorization into "subfleets"), the data also included trip-level information such as fishing time, catches, revenues, gear and métier, broken down by day and species and aggregated by $\frac{1}{20}^{\circ} \times \frac{1}{20}^{\circ}$ statistical squares (about $\left.3 \mathrm{NM} \times 2 \mathrm{NM}\right)$.

We categorized vessels into fleet segments based on the métiers used by vessels as identified in the data set, and on European Data Collection Framework definition of fishing fleets. 


\section{Discrete-Choice Model}

\section{Model selection}

\section{Additional explanatory variables}

We originally included in the model a couple of additional variables aimed at explicitly capturing sites' heterogeneity in terms of catch composition. Namely, we estimated Eq.1 for a sub-sample of the data and for five key species adding in a linear way:

$\mathrm{Sh}_{s d j}^{\mathrm{exp}}$ : the expected share of species $\mathrm{s}$ in total catch from site $j$, proxy by a combination of the fleet historical records of share of landing value from species s over the past month and over the same 30 days period of the past year;

- Diversity ${ }_{d j}^{\exp }$ : the expected species diversity for site $j$, proxy by a combination of the fleet historical records of species diversity over the past month and over the same 30 days period of the past year;

The species diversity of a given site is captured by the entropy index of species value shares: Diversity $_{d j}=\sum_{s}-\mathrm{Sh}_{s d j} * \ln \left(\mathrm{Sh}_{s d j}\right)$. It is inspired from the measures of services' diversity used in the transportation literature (Huang and Levinson, 2015).

However, those additional variables revealed to be not significant and we chose to drop them for further analysis.

\section{VPUE expectations}

In order to find a specification of the expected VPUE that would the most closely capture fishers' actual expectations, we estimated, separately for each fleet on which we focus in the 
paper, Eq. 1 with 11 different combinations of information signals for the expected VPUE (Table B.1).

Table B.1 Combinations of information signals considered for the specification of the expected VPUE

\begin{tabular}{|c|c|c|c|c|c|c|c|}
\hline \multirow[t]{2}{*}{ Model \# } & \multirow{2}{*}{$\begin{array}{l}\text { Info. } \\
\text { Source } \\
\text { Time } \\
\text { span } \\
\end{array}$} & \multicolumn{3}{|c|}{ Individual level } & \multicolumn{3}{|c|}{ Fleet level } \\
\hline & & $\begin{array}{c}{[\mathrm{t} ; \mathrm{t}-30]} \\
(\mathrm{m} 1)\end{array}$ & $\begin{array}{c}{[\mathrm{t} ; \mathrm{t}-365]} \\
(\mathrm{y} 1)\end{array}$ & $\begin{array}{c}{[\mathrm{t}-350 ; \mathrm{t}-370]} \\
(\mathrm{ym} 1)\end{array}$ & $\begin{array}{c}{[\mathrm{t} ; \mathrm{t}-30]} \\
(\mathrm{m} 1)\end{array}$ & $\begin{array}{c}{[\mathrm{t} ; \mathrm{t}-365]} \\
(\mathrm{y} 1)\end{array}$ & $\begin{array}{c}{[\mathrm{t}-350 ; \mathrm{t}-370]} \\
(\mathrm{ym} 1)\end{array}$ \\
\hline 1 & & $\mathrm{~N}$ & $\mathrm{~N}$ & $\mathrm{~N}$ & Y & $\mathrm{N}$ & $\mathrm{N}$ \\
\hline 2 & & $\mathrm{~N}$ & $\mathrm{~N}$ & $\mathrm{~N}$ & $\mathrm{~N}$ & $\mathrm{Y}$ & $\mathrm{N}$ \\
\hline 3 & & $\mathrm{~N}$ & $\mathrm{~N}$ & $\mathrm{~N}$ & $\mathrm{~N}$ & $\mathrm{~N}$ & Y \\
\hline 4 & & Y & $\mathrm{N}$ & $\mathrm{N}$ & Y & $\mathrm{N}$ & $\mathrm{N}$ \\
\hline 5 & & $\mathrm{~N}$ & Y & $\mathrm{N}$ & $\mathrm{N}$ & Y & $\mathrm{N}$ \\
\hline 6 & & $\mathrm{~N}$ & $\mathrm{~N}$ & Y & $\mathrm{N}$ & $\mathrm{N}$ & Y \\
\hline 7 & & $\mathrm{~N}$ & $\mathrm{~N}$ & $\mathrm{~N}$ & Y & Y & $\mathrm{N}$ \\
\hline 8 & & $\mathrm{~N}$ & $\mathrm{~N}$ & $\mathrm{~N}$ & $\mathrm{Y}$ & $\mathrm{N}$ & Y \\
\hline 9 & & $\mathrm{~N}$ & $\mathrm{~N}$ & $\mathrm{~N}$ & $\mathrm{~N}$ & $\mathrm{Y}$ & Y \\
\hline 10 & & $\mathrm{~N}$ & $\mathrm{~N}$ & $\mathrm{~N}$ & Y & Y & Y \\
\hline 11 & & Y & $\mathrm{N}$ & Y & Y & $\mathrm{N}$ & Y \\
\hline
\end{tabular}

For each combination of information signals we allow the marginal utility of the expected VPUE to vary according to which combination of information is available. In practice, this means that for a given specification of the expected VPUE we interact dummies associated with a given case of information availability. For instance, for model 8 that accounts for both short-term and long-term information signals but only at the fleet-level, the specification for the expected VPUE is: 


$$
\begin{aligned}
& \beta_{\mathrm{VPUE}} * \mathrm{E}[\mathrm{VPUE} \mathrm{ijt}] \\
& =\left\{\begin{array}{c}
\beta_{\mathrm{VPUE}}^{\text {Full info-short-term }} * \overline{\mathrm{VPUE}}_{\mathrm{m}-1}^{\mathrm{ft}}+\beta_{\mathrm{VPUE}}^{\text {Full info-long-term }} * \overline{\mathrm{VPUE}}_{\mathrm{ym}-1}^{\mathrm{ft}} \text { if case } 1 \\
\beta_{\mathrm{VPUE}}^{\text {Short-term only }} * \overline{\mathrm{VPUE}}_{\mathrm{m}-1}^{\mathrm{tt}} \text { if case } 2 \\
\beta_{\mathrm{VPUE}}^{\text {Long-term only }} * \overline{\mathrm{VPUE}}_{\mathrm{yt}-1}^{\mathrm{ft}} \text { if case } 3 \\
\beta_{\mathrm{VPUE}}^{\text {No info }} \text { if case } 4
\end{array}\right.
\end{aligned}
$$

With:

- case 1: both short-term and long-term historical VPUE are available

- case 2: only short-term historical VPUE are available

- case 3: only long-term historical VPUE are available

- case 4: neither short-term or long-term historical VPUE are available

\section{Model selection}

We then selected the best model for each fleet using the AIC. In the end the specifications showed very similar performances in terms of goodness of fit, even though Model 11 revealed to be systematically the best model for all the fleets (Table B.2).

Table B.2 $\triangle$ AIC with model 11 of the different model's specifications tried, by segment fleet and spatial configuration.

\begin{tabular}{r|ccc|ccc|ccc|}
\cline { 2 - 9 } Model & \multicolumn{3}{|c|}{ BTR exc $>=18 \mathrm{~m}$} & \multicolumn{3}{c|}{ BTR dom $>=18 \mathrm{~m}$} & \multicolumn{3}{c|}{ TRP $>=12 \mathrm{~m}$} \\
\hline 1 & 16086 & 21192 & 23530 & 3297 & 3846 & 4228 & 461 & 623 & 710 \\
2 & 16313 & 22262 & NA & 3625 & 4585 & 5140 & 525 & 762 & 908 \\
3 & 16181 & 21586 & 24413 & 3386 & 4287 & 4775 & 475 & 631 & 784 \\
4 & 2438 & 4269 & 5302 & 431 & 642 & 756 & 151 & 201 & 223 \\
5 & 4962 & 5877 & NA & 1457 & 1795 & 2140 & 186 & 261 & 280 \\
6 & 6571 & 10192 & 12109 & 2173 & 2924 & 3252 & 173 & 265 & 410 \\
7 & 16050 & 21176 & NA & 3246 & 3829 & 4209 & 460 & 615 & 705 \\
8 & 15993 & 20983 & 23218 & 3065 & 3698 & 4090 & 443 & 567 & 651 \\
9 & 16097 & 21527 & NA & 3250 & 4143 & 4661 & 477 & 623 & 775 \\
10 & 15980 & NA & NA & 2989 & 3661 & 4049 & 449 & 564 & 658 \\
11 & 0 & 0 & 0 & 0 & 0 & 0 & 0 & 0 & 0 \\
\cline { 2 - 9 }
\end{tabular}




\begin{tabular}{r|ccc|ccc|} 
& \multicolumn{3}{|c|}{ DFN $>=12 \mathrm{~m}$} & \multicolumn{3}{|c|}{ DRD $>=12 \mathrm{~m}$} \\
Model & $2^{\circ} \times 2^{\circ}$ & $\mathrm{ICES}$ & $1 / 2^{\circ} \times 1 / 2^{\circ}$ & $2^{\circ} \times 2^{\circ}$ & $\mathrm{ICES}$ & $1 / 2^{\circ} \times 1 / 2^{\circ}$ \\
\cline { 2 - 7 } & 10034 & 15135 & 16850 & 2506 & 5746 & 6774 \\
2 & 11437 & 17744 & 19743 & 2538 & 6439 & 7959 \\
3 & 10498 & 16413 & 18390 & 2,293 & 3,879 & $\mathrm{NA}$ \\
4 & 1115 & 1809 & 2182 & -398 & 839 & 1051 \\
5 & 2955 & 4637 & 5148 & 613 & 3055 & 3595 \\
6 & 4800 & 9520 & 11569 & 1142 & 3720 & 4601 \\
7 & 9921 & 15062 & 16742 & 2325 & 5723 & 6774 \\
8 & 9827 & 14719 & 16210 & 2393 & 5498 & 6386 \\
9 & $\mathrm{NA}$ & 16162 & 18028 & 2330 & 5931 & 7099 \\
10 & 9784 & 14637 & 16192 & 2295 & 5498 & 6390 \\
11 & 0 & 0 & 0 & 0 & 0 & 0 \\
\hline
\end{tabular}

\section{Model's estimates}

Table B.3 Average marginal effects of the explanatory variables of the discrete-choice model of fishing locations for an increase of 1 standard deviation. Significance levels: $0.1 \% * * *, 1 \% * *$, $5 \% *, 10 \%$.

\begin{tabular}{|c|c|c|c|c|}
\hline & & $2^{\circ} \times 2^{\circ}$ & ICES & $1 / 2^{\circ} X^{1 / 2}{ }^{\circ}$ \\
\hline \multirow{5}{*}{ Dist.d1 } & BTR exc $>=18 \mathrm{~m}$ & $\mathbf{- 0 . 0 5} * * *$ & $-0.041 * * *$ & $-0.153 * * *$ \\
\hline & BTR dom $>=18 \mathrm{~m}$ & $-0.166 * * *$ & $-0.328 * * *$ & $-0.426 * * *$ \\
\hline & $\mathrm{TRP}>=12 \mathrm{~m}$ & -0.007 & $-0.058 * * *$ & $-0.087 * * *$ \\
\hline & $\mathrm{DFN}>=12 \mathrm{~m}$ & $-0.029 * * *$ & $-0.091 * * *$ & $-0.252 * * *$ \\
\hline & $\mathrm{DRD}>=12 \mathrm{~m}$ & $-0.088 * * *$ & $-0.132 * * *$ & $-0.176 * * *$ \\
\hline \multirow{5}{*}{ N.vs.other.ft.d1 } & BTR exc $>=18 m$ & $0.012 * * *$ & $0.006 * * *$ & $0.017 * * *$ \\
\hline & BTR dom $>=18 \mathrm{~m}$ & $0.031 * * *$ & $0.024 * * *$ & $0.026 * * *$ \\
\hline & $\mathrm{TRP}>=12 \mathrm{~m}$ & $0.019 * * *$ & $0.022 * * *$ & $0.03 * * *$ \\
\hline & $\mathrm{DFN}>=12 \mathrm{~m}$ & $0.003 * * *$ & $0.009 * * *$ & $0.021 * * *$ \\
\hline & $\mathrm{DRD}>=12 \mathrm{~m}$ & $0.011 * * *$ & $0.019 * * *$ & $0.02 * * *$ \\
\hline \multirow{5}{*}{ N.vs.same.ft.d1 } & BTR exc $>=18 m$ & $-0.993 * * *$ & $-0.469 * * *$ & $-1.349 * * *$ \\
\hline & BTR dom $>=18 \mathrm{~m}$ & $-1.471 * * *$ & $-2.178 * * *$ & $-2.504 * * *$ \\
\hline & $\mathrm{TRP}>=12 \mathrm{~m}$ & $-0.678 * * *$ & $-1.272 * * *$ & $-1.399 * * *$ \\
\hline & $\mathrm{DFN}>=12 \mathrm{~m}$ & $-1.108 * * *$ & $-1.74 * * *$ & $-4.256 * * *$ \\
\hline & $\mathrm{DRD}>=12 \mathrm{~m}$ & $-1.135 * * *$ & $-2.854 * * *$ & $-3.426 * * *$ \\
\hline \multirow{2}{*}{ Act.own } & BTR exc $>=18 m$ & $0.006 * * *$ & $0.002 * * *$ & $0.005 * * *$ \\
\hline & BTR dom $>=18 \mathrm{~m}$ & $0.011 * * *$ & $0.009 * * *$ & $0.009 * * *$ \\
\hline
\end{tabular}




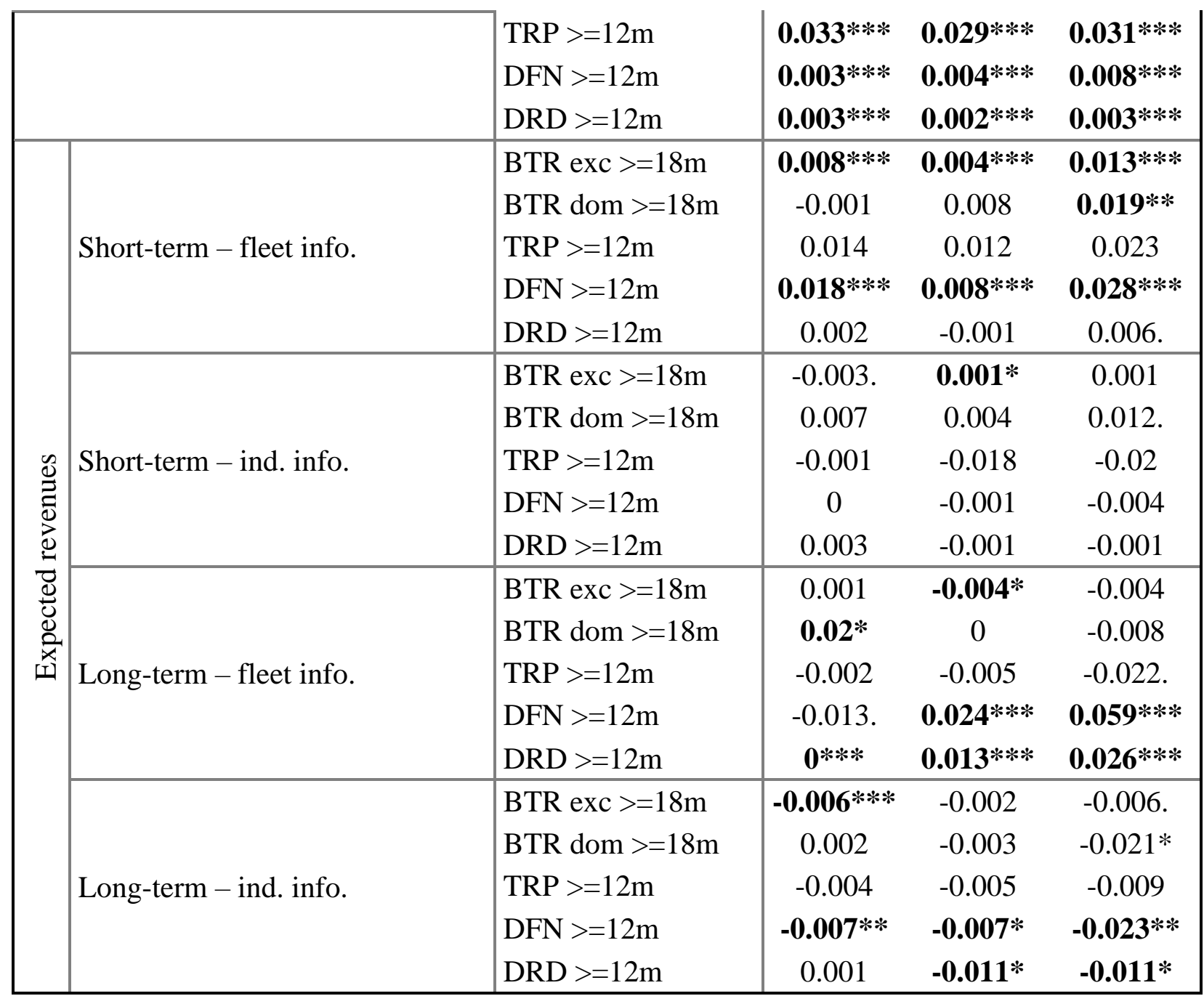


Table B.4 Marginal rates of substitution with distance of the explanatory variables of the discretechoice model of fishing locations. For each fleet segment the parameters shown are those obtained using the appropriate spatial resolution for defining fishing site options, i.e. $2^{\circ} \times 2^{\circ}$ squares for the two segments of bottom trawlers and ICES squares for the other. Significance levels: $0.1 \% * * *, 1 \% * *$, $5 \% *, 10 \%$.

\begin{tabular}{|c|c|c|c|c|c|c|c|}
\hline & & $\begin{array}{c}\text { Bottom Trawl } \\
\text { exc. } \geq 18 m\end{array}$ & $\begin{array}{c}\text { Bottom Trawl } \\
\text { dom. } \geq 18 m\end{array}$ & $\begin{array}{c}\text { Pots \& } \\
\text { Traps } \geq 12 m \\
\end{array}$ & $\begin{array}{c}\text { Drift \& Fixed } \\
\text { Nets } \geq 12 m\end{array}$ & Dredge $\geq 12 m$ & Unit \\
\hline \multirow{2}{*}{$\begin{array}{l}\text { \# of other } \\
\text { vessels }\end{array}$} & Other fleets & $-1.21 \mathrm{e}-01 * * *$ & $-2.27 \mathrm{e}-01 * * *$ & $-5.59 \mathrm{e}-01 * *$ & $-1.99 \mathrm{e}-01 * * *$ & $-2.19 \mathrm{e}-02 * * *$ & $100 \mathrm{~km} / \mathrm{Nb}$. \\
\hline & Same fleet & $4.21 \mathrm{e}+00 * * *$ & $3.22 \mathrm{e}+00 * * *$ & $8.87 \mathrm{e}+00 * * *$ & $3.45 \mathrm{e}+00^{* * *}$ & $9.62 \mathrm{e}-01 * * *$ & Vessels \\
\hline \multicolumn{2}{|c|}{$\begin{array}{c}\text { Vessel's past fishing } \\
\text { effort }\end{array}$} & $-5.31 \mathrm{e}+00 * * *$ & $-5.86 e+00 * * *$ & $-1.43 e+02 * *$ & $-1.27 \mathrm{e}+01 * * *$ & $-1.72 \mathrm{e}+00 * * *$ & $100 \mathrm{~km} / \mathrm{h}$ \\
\hline \multirow{4}{*}{$\begin{array}{l}\text { Expected } \\
\text { revenues* }\end{array}$} & \multirow{4}{*}{$\begin{array}{l}\text { Short-term - } \\
\text { fleet VPUE } \\
\text { Short-term - } \\
\text { ind. VPUE } \\
\text { Long-term - } \\
\text { fleet VPUE } \\
\text { Long-term - } \\
\text { ind. VPUE }\end{array}$} & $-1.96 \mathrm{e}-02 * * *$ & $2.70 \mathrm{e}-03$ & $-9.72 e-04$ & $-4.94 \mathrm{e}-04 *$ & $4.98 \mathrm{e}-06$ & $\begin{array}{l}100 \\
\mathrm{~km} /(€ / \mathrm{h})\end{array}$ \\
\hline & & $-1.79 \mathrm{e}-04$ & $-1.50 \mathrm{e}-03$ & $2.71 \mathrm{e}-03$ & $7.74 \mathrm{e}-05$ & $-4.05 e-06$ & $\begin{array}{l}100 \\
\mathrm{~km} /(€ / \mathrm{h})\end{array}$ \\
\hline & & $-2.37 \mathrm{e}-03$ & $-3.26 \mathrm{e}-03$ & $6.23 e-04$ & $-1.60 \mathrm{e}-03 * * *$ & $-1.31 \mathrm{e}-03 * * *$ & $\begin{array}{l}100 \\
\mathrm{~km} /(€ / \mathrm{h})\end{array}$ \\
\hline & & $1.14 \mathrm{e}-02 * * * *$ & $-2.74 \mathrm{e}-04$ & $5.06 \mathrm{e}-04$ & $6.16 \mathrm{e}-04 *$ & $1.12 \mathrm{e}-04 *$ & $\begin{array}{l}100 \\
\mathrm{~km} /(€ / \mathrm{h})\end{array}$ \\
\hline
\end{tabular}

*Reported estimates for the expected revenues are those in the case where all the four types of information (individual and fleet-level, short and long-term) are available.

A marginal rate of substitution with distance of $-100 \mathrm{~km} /(\epsilon / \mathrm{h})$ means that $1 € / \mathrm{h}$ of expected revenues compensates for the disutility of going to a fishing ground which is $100 \mathrm{~km}$ further.

Besides the expected significant negative effect of distance, we find a significant positive effect of the lagged number of other vessels of other fleet segments fishing on a site on the probability of visit for this same site, and a significant negative effect of the lagged number of other vessels of the same fleet segment fishing on a site on the probability of visit for this same site. These opposed both effects would suggest a repulsive effect from the competition with vessels sharing the same métier combined with a herding behavior (not undermined by a potential congestion effect) of fishers with respect to fishers of other métiers, which presumably concentrates in the most productive sites, but do not necessarily target the same species. The discrete-choice literature has reported various effects regard the effect of other fishers (Girardin et al., 2016). Girardin (2015) for instance found that the contemporaneous presence of other 
French vessels in a given site in the English Channel often had a significant negative effect on the choice of a fishing location. However, they also found that the presence of English vessels had a positive effect, which they explain by the fact that some French and English fleet segments targets scallops, a lowly mobile species. Similarly, Russo et al. (2015) reported an attractive effect on the direction location choice of pair trawlers from fishing units but a repulsion effect from vessels that are not fishing. At last, Abbott and Wilen (2011) reported in their Appendix, a positive effect of other vessels' presence in a site with a one-day lag but a negative effect with a two-day or three-day lag. In our definition of the activity of other vessels we pooled together vessels from all the fleet segments for which we had a full VMS coverage, i.e. all vessels with a length over all larger than $12 \mathrm{~m}$. Data allowing, it would be interesting for future work to see whether that herding effect persists when including smaller vessels as well.

We find as well a consistent positive and significant effect of vessels' own fishing effort on a given site the day before. This means that vessels are more likely to stay fishing in the same ground rather than to move to exploit another fishing site. This findings is in line with the general result in the literature which usually reports - though over sometimes different timewindows - a significant positive effect of past fishing patterns (Abbott and Wilen, 2011; Girardin et al., 2016, 2015; Hynes et al., 2016).

The most surprising results in terms of model's parameters estimates are perhaps those regarding the sign and the significance of the variables related to the expected productivity of the sites. First, we find highly differentiated effects across the five fleet segments which supports our approach of estimating segment-specific models for vessels having fundamentally different fishing strategies. Second, we also find differentiated effects depending on the type of information that is considered. This validates our approach of distinguishing between segment- 
level (public) and vessel-level (private) information, which is still rarely undertaken in the literature where most models usually only consider fleet-level aggregates (Girardin et al., 2016). Our results suggest that fishers primarily base their expectations on fleet-level information but correcting it accordingly with their own individual experience, when available.

For exclusive bottom trawlers, we find that short-term public information has a positive effect and long-term private information has a negative effect. This combination can appear intuitive for vessels targeting highly mobile species with changing seasonal spatial pattern: the value of information deprecates quickly and vessels are better off basing their expectations on a larger pool of information sources or on tracking technologies equipping the majority of vessels in the segment.

For large dominant bottom trawlers the story appears to be different: only long-term public information is found to be significant, with a positive effect on the probability of choice of a site. To explain this somewhat counter-intuitive findings, we can follow some of the arguments of Girardin \& al. (2015) who report a negative effect of past segment-level productivity in the short-term (one month lag) for mid-size demersal trawlers. While they explain those negative estimates by a lack of capacity to respond to change in fisheries productivity in the short-term and by the result of specific seasonality changes in species abundance in the long-term. Another explanation could also be related to deprecation rate of information. It may be the case that, depending on the type of targeted species - which may vary greatly within this segment - fishes are so mobile from day to day or week to week that there is a lower probability of finding them in the same locations over a four week interval. To test this hypothesis, it would be interesting to see whether the sign and the significance of the effect changes when choosing tighter time- 
windows (based on weeks instead on months for instance) for computing the average historical productivities.

Noticeably, we find that none of the VPUE-related variables are significant in the case of vessels using pots and traps, even when considering each type of possible information configurations or different spatial scales. Conversely, for the other one-day lagged and nonrevenue related variables, this fleet segment exhibits the highest MRS with distance among all the fleet segment (see Table B.4). Such a pattern would be consistent with fish stocks that are not very mobile resulting in an observed highly spatially concentrated fishing sites (see Figure C.3), where fishers tend to stick to their fishing habits while adjusting their fishing choices according to the observed presence of other vessels.

Dredgers display a different pattern as well: while public or private information have no significant effect in the short-term, both of them have a significant effect in the longer-term, with a positive effect for fleet-based information mitigated by a negative effect for vessel-specific information. An explanation for these opposite effects could be that fishers would correct their expectation base on fleet segment aggregates when their own experience diverges from the segment average. The difference in the significance of short-term and long-term information could also stem from the mobility pattern of the targeted species. Scallops are the main target species of dredgers. In the short-run, dredging is similar to clear-cutting and therefore short-term past information is not likely to impact current location choices. At the same time, the bottom structure that leads to the sites being the most productive is probably correlated with the sites ability to recover from dredging and therefore, the most productive sites might not change very much from year to year. 


\section{Maps of the impact of the closures of the UK EEZ on the allocation of fishing effort of the selected fleets}

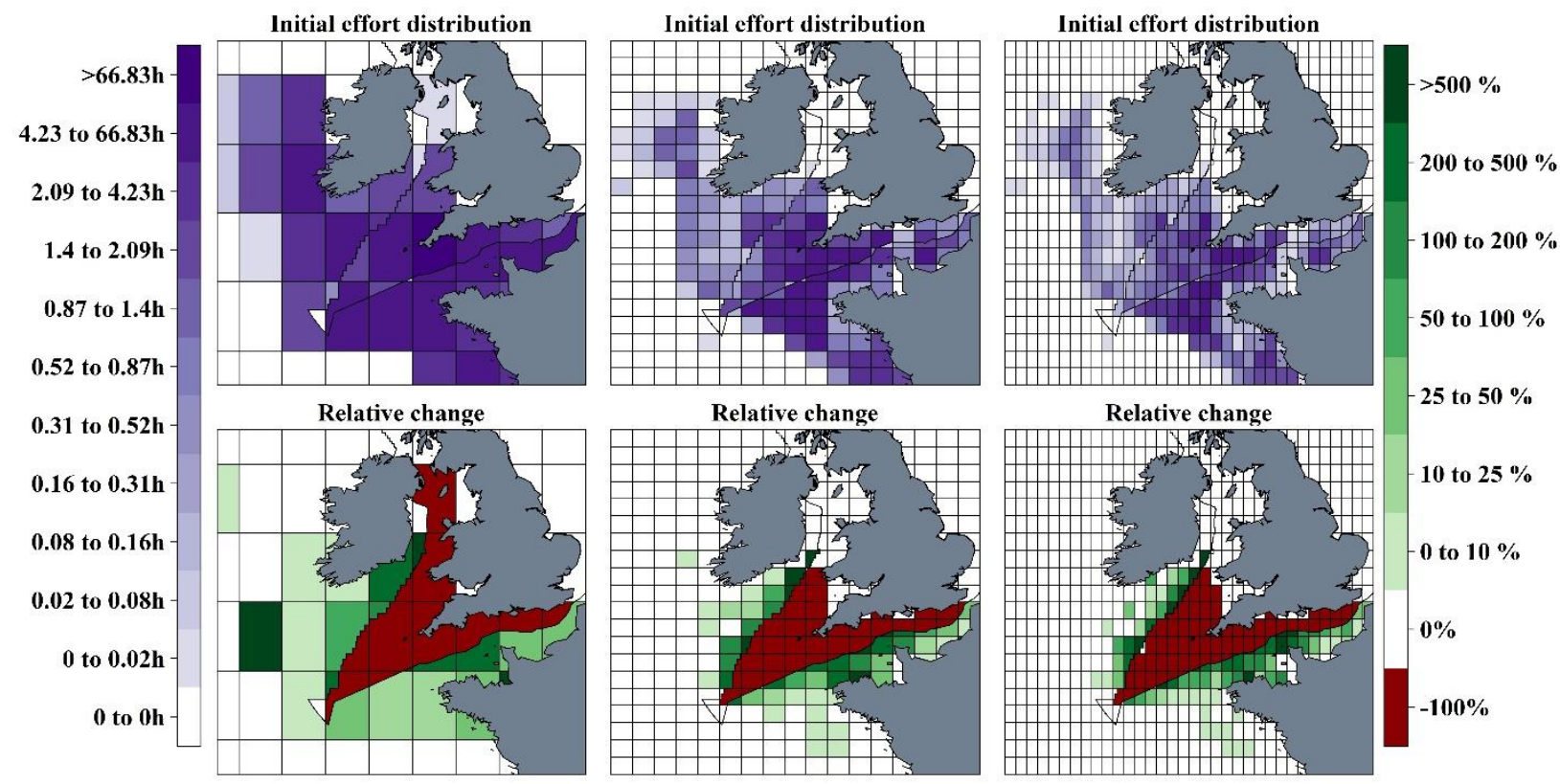

Figure D.1 Simulation of the reallocation of fishing effort due to the closure of the UK EEZ for BTR exc $>=18 \mathrm{~m}$ vessels. The upper panels (left purple color key) show the spatial distribution of effort for 2015 by deciles. The bottom panels (right green and red color key) show the relative change in the mean daily fishing effort . 


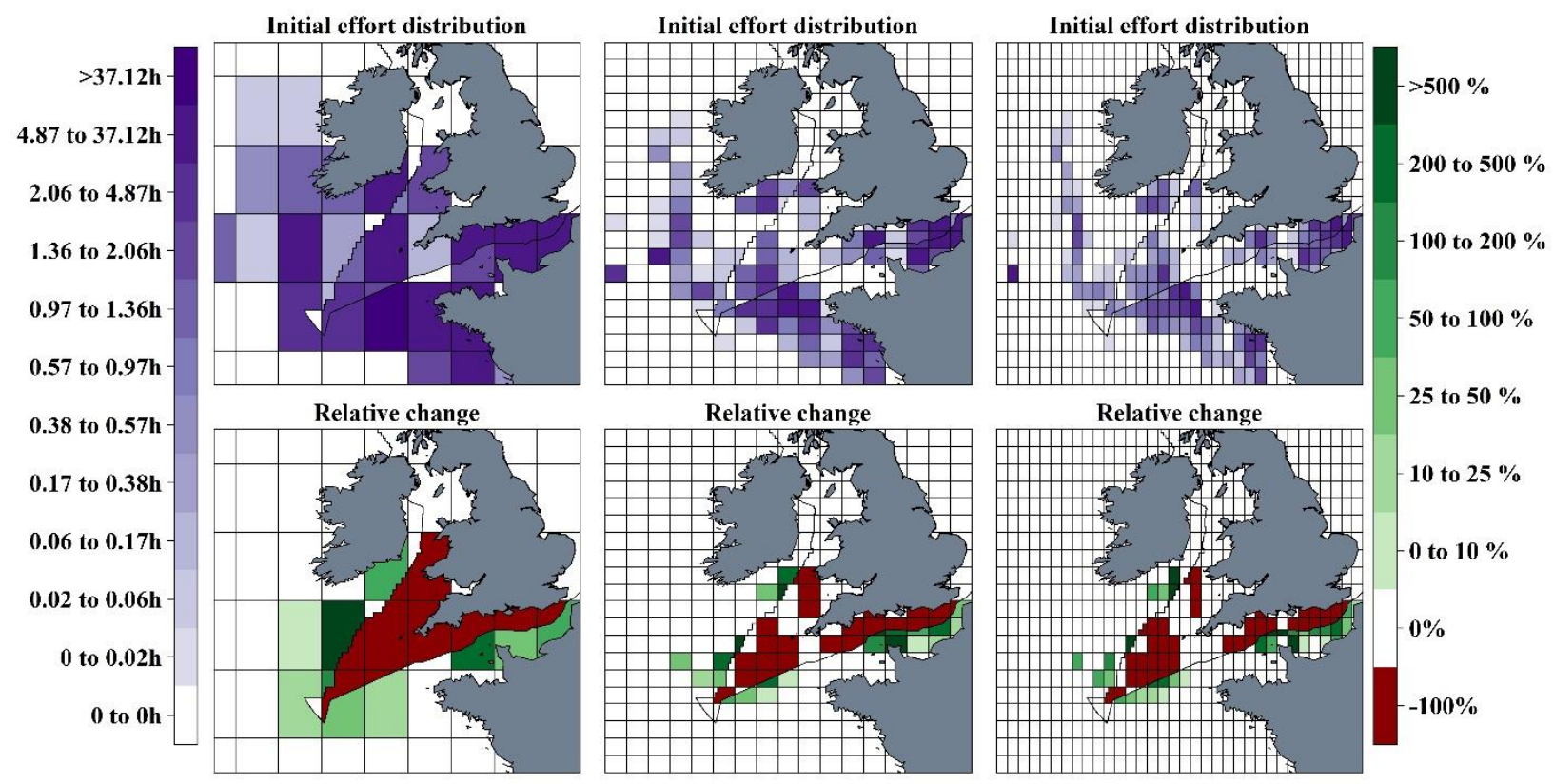

Figure D.2 Simulation of the reallocation of fishing effort due to the closure of the UK EEZ for BTR dom $>=18 \mathrm{~m}$ vessels. The upper panels (left purple color key) show the spatial distribution of effort for 2015 by deciles. The bottom panels (right green and red color key) show the relative change in the mean daily fishing effort. 


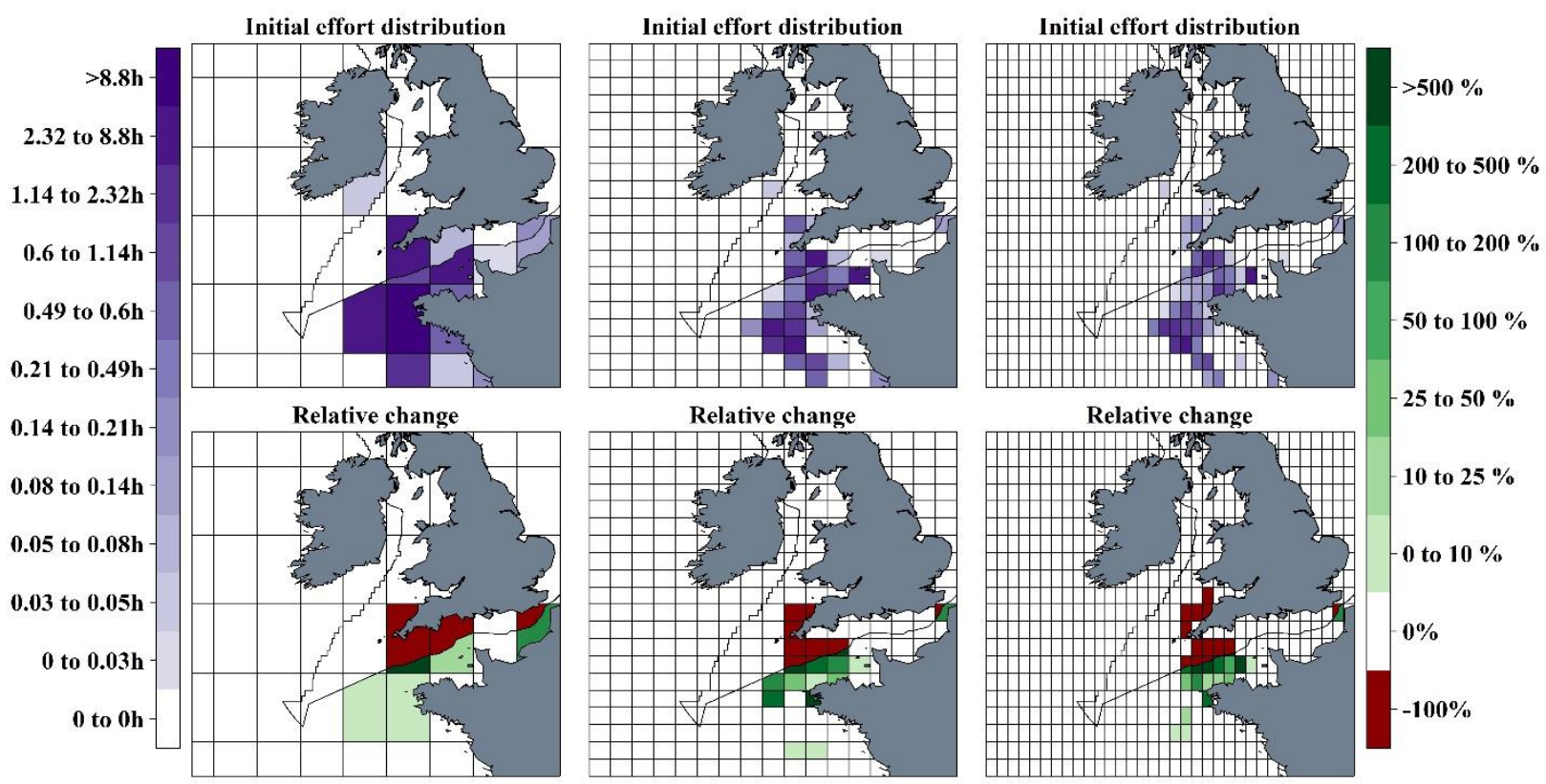

Figure D.3 Simulation of the reallocation of fishing effort due to the closure of the UK EEZ for TRP $>=12 \mathrm{~m}$ vessels. The upper panels (left purple color key) show the spatial distribution of effort for 2015 by deciles. The bottom panels (right green and red color key) show the relative change in the mean daily fishing effort. 


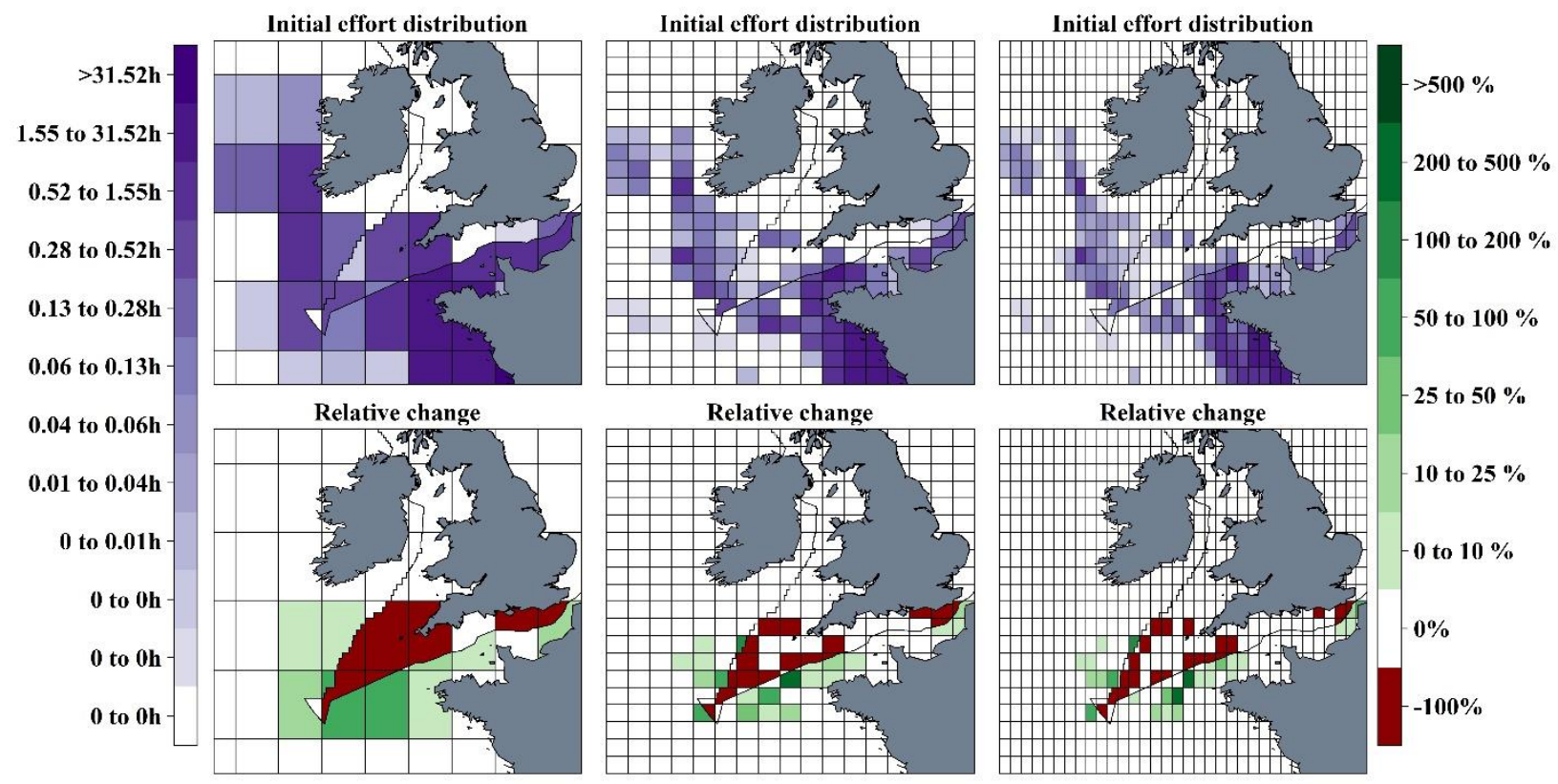

Figure D.4 Simulation of the reallocation of fishing effort due to the closure of the UK EEZ for DFN $>=12 \mathrm{~m}$ vessels. The upper panels (left purple color key) show the spatial distribution of effort for 2015 by deciles. The bottom panels (right green and red color key) show the relative change in the mean daily fishing effort . 


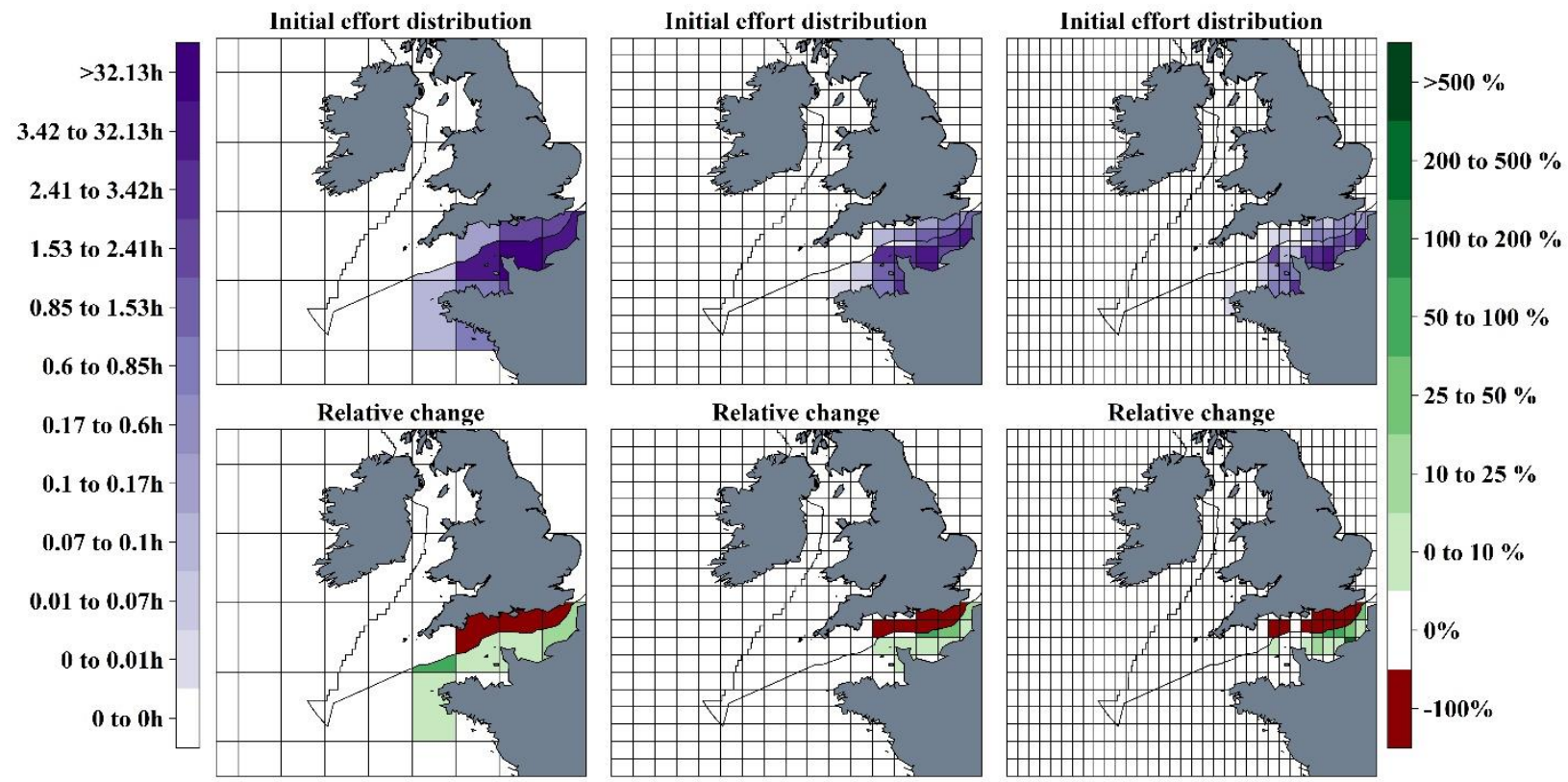

Figure D.5 Simulation of the reallocation of fishing effort due to the closure of the UK EEZ for DRD $>=12 \mathrm{~m}$ vessels. The upper panels (left purple color key) show the spatial distribution of effort for 2015 by deciles. The bottom panels (right green and red color key) show the relative change in the mean daily fishing effort. 


\section{E. Complementary results}

\section{Accounting for the first day of a fishing trip}

A limitation of our model is that it does not account for the heterogeneity of fishing choices during multi-day trips. In particular, suggested by Kuriyama et al. (2019) for instance, the weight of choices' explanatory factors are likely to be different for the first day of trip, for which fishers may travel to farther fishing sites. To test this hypothesis we re-estimated the selected model, but we interacted a dummy for the first day of a trip with the distance to the fishing sites. Table E.1.a shows the resulting estimates for the distance variable with this alternative model. When looking at the spatial scale deemed relevant for each fleet segment, estimates remain close to one another.

Table E.1 Average marginal effects of the distance to fishing sites for an increase of 1 standard deviation. Significance levels: $0.1 \% * * *, 1 \% * *, 5 \% *, 10 \%$..

\begin{tabular}{|c|c|c|c|c|c|c|c|c|c|}
\hline \multirow[b]{3}{*}{ Fleet segment } & \multicolumn{3}{|c|}{$2^{\circ} \times 2^{\circ}$} & \multicolumn{3}{|c|}{ ICES } & \multicolumn{3}{|c|}{$1 / 2^{\circ} \times 1 / 2^{\circ}$} \\
\hline & \multirow{2}{*}{$\begin{array}{c}\begin{array}{c}\text { Base } \\
\text { model }\end{array} \\
\text { Any day }\end{array}$} & \multicolumn{2}{|c|}{ Alternative model } & \multirow{2}{*}{$\begin{array}{c}\begin{array}{c}\text { Base } \\
\text { model }\end{array} \\
\text { Any day }\end{array}$} & \multicolumn{2}{|c|}{ Alternative model } & \multirow{2}{*}{$\begin{array}{c}\begin{array}{c}\text { Base } \\
\text { model }\end{array} \\
\text { Any day }\end{array}$} & \multicolumn{2}{|c|}{ Alternative model } \\
\hline & & Later day & First day & & Later day & First day & & Later day & First day \\
\hline BTR exc $>=18 \mathrm{~m}$ & $-0.05 * * *$ & $-0.052 * * *$ & $-0.044 * * *$ & $-0.041 * * *$ & $-0.068 * * *$ & $-0.023 * * *$ & $-0.153 * * *$ & $-0.258 * * *$ & $\mathbf{- 0 . 0 7 7 * * *}$ \\
\hline BTR dom $>=18 \mathrm{~m}$ & $-0.166 * * *$ & $-0.179 * * *$ & $-0.187 * * *$ & $-0.328 * * *$ & $-0.554 * * *$ & $-0.295 * * *$ & $-0.426 * * *$ & $-0.797 * * *$ & $-0.372 * * *$ \\
\hline $\mathrm{TRP}>=12 \mathrm{~m}$ & -0.007 & -0.028 & -0.001 & $-0.058 * * *$ & $-0.115 * *$ & $\mathbf{- 0 . 0 3 5 * *}$ & $-0.087 * * *$ & $-0.272 * * *$ & $-0.039 *$ \\
\hline DFN $>=12 \mathrm{~m}$ & $-0.029 * * *$ & $-0.029 * * *$ & $-0.029 * * *$ & $-0.091 * * *$ & $-0.178 * * *$ & $-0.073 * * *$ & $-0.252 * * *$ & $-0.492 * * *$ & $-0.185^{* * *}$ \\
\hline DRD $>=12 \mathrm{~m}$ & $-\mathbf{0 . 0 8 8} * * *$ & $-0.023 * * *$ & $-0.048 * * *$ & $-0.132 * * *$ & $-0.122 * * *$ & $-0.145 * * *$ & $-0.176 * * *$ & $-0.193 * * *$ & $-0.187 * * *$ \\
\hline
\end{tabular}

The hypothesis of a lesser effect of distance for the first day of a trip is validated for the all but one - dredgers - fleet segments and for all spatial resolutions except the coarsest one. At the coarsest resolution, only exclusive bottom trawlers display a significantly disutility of distance during the first day of their fishing trip. Dominant bottom trawlers and netters display the opposite pattern and estimates for vessels using pots and traps are not significant. Dredgers 
are found to be systematically less likely to choose farther fishing sites during their first day of trip than during later days. This pattern may not be surprising when observing the spatial distribution of the fishing effort of dredgers: it is very highly concentrated near the French shores, in the narrowest part of the Channel suggesting this fleet segments favor shorter trips in general. The changing pattern of dominant bottom trawlers and netters when decreasing the spatial resolution is perhaps more surprising. Nonetheless, an explanation for this could also be related to the closeness to the shores of the fishing effort distribution of these fleet segments, combined with the large extent of the fishing sites in the coarsest resolution. Even though vessels may travel farther during their first day of trips, their chosen fishing location may remain included in the $2^{\circ} \times 2^{\circ}$ square which is nearest to their point of departure. In this sense, this exemplifies even more the importance of testing different spatial configurations and spatial scales when estimating a discrete-choice model.

Accounting for this nuance in the choice of the fishing location of the first days of trips can have mixed implications for the re-allocation of effort that is predicted by the model. On one side, sites that are located close to the French shores may be predicted to be less likely chosen, thereby alleviating part of the fishing intensification in the Channel for instance. However, on the other side it may also lead sites located near the south west end of the UK EEZ to be predicted to be more likely chosen, thereby increasing the fishing pressure in this area.

\section{Accounting for the dynamic behavior of fishers}

Another important limitation of our modeling efforts is that we do not account for the dynamic nature of fisher behavior. That is, fishers are likely to update their decisions through time as the spatial closure remains. We attempted to assess the implications of such dynamic behavior on effort re-allocation and welfare losses by re-running the discrete-choice model 
allowing the day-to-day predictions to be updated. In order to so, we need to make an assumption regarding how the variables related to the productivity of vessels in each of the potentially selected sites are updated over time. Being unable to observe the contemporaneous productivity of vessels in the consecutively chosen sites, we used historical values as proxies. Depending on the information available, we primarily used short-term productivity (i.e., average over the last 30 days) - preferably computed at the vessel level if possible - before turning to long-term information (i.e. past productivity over the 30 days surrounding the same period of the past year) - also preferably computed at the vessel level. If no information was available at all, we set the productivity in the selected site to 0 . Because of this important caveat as well as because of the intensiveness of the computations - values have to be updated accounting for the predictions for each vessel of all the five fleet segments for each day - we made predictions only for the first 30 days of 2015, and tested only the two coarsest resolutions.

Figures E.1 to E.4 show the difference in the effort re-allocation when using "static" or "dynamic" predictions (vessels using pots and traps did not take fishing trips in January 2015). As expected, we observe a spatially larger dispersion of the effort re-allocation which is predicted to be smoothed across contiguous sites when chaining the predictions. Notably, with such "dynamic" predictions, the increase fishing pressure in the sites neighboring the UK EEZ for January 2015 at least - is found to be partially alleviated toward sites located west of Ireland and in the Bay of Biscay. 


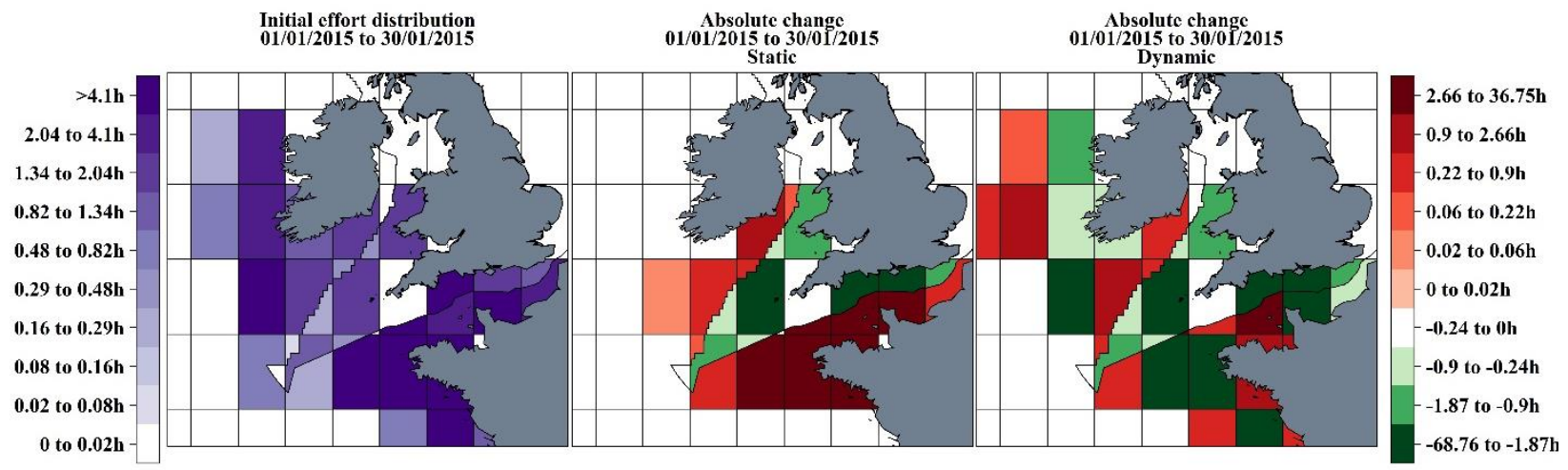

Figure E.1 Simulations of the reallocation of fishing effort due to the closure of the UK EEZ for BTR exc. >= 18m vessels when using static or dynamic predictions. The left panel (left purple color key) show the spatial distribution of effort between 01/01/2015 to 30/01/2015. The center and right panels (right green and red color key) show the absolute change in the mean daily fishing effort (in hours of fishing) when using "static" or "dynamic" predictions.

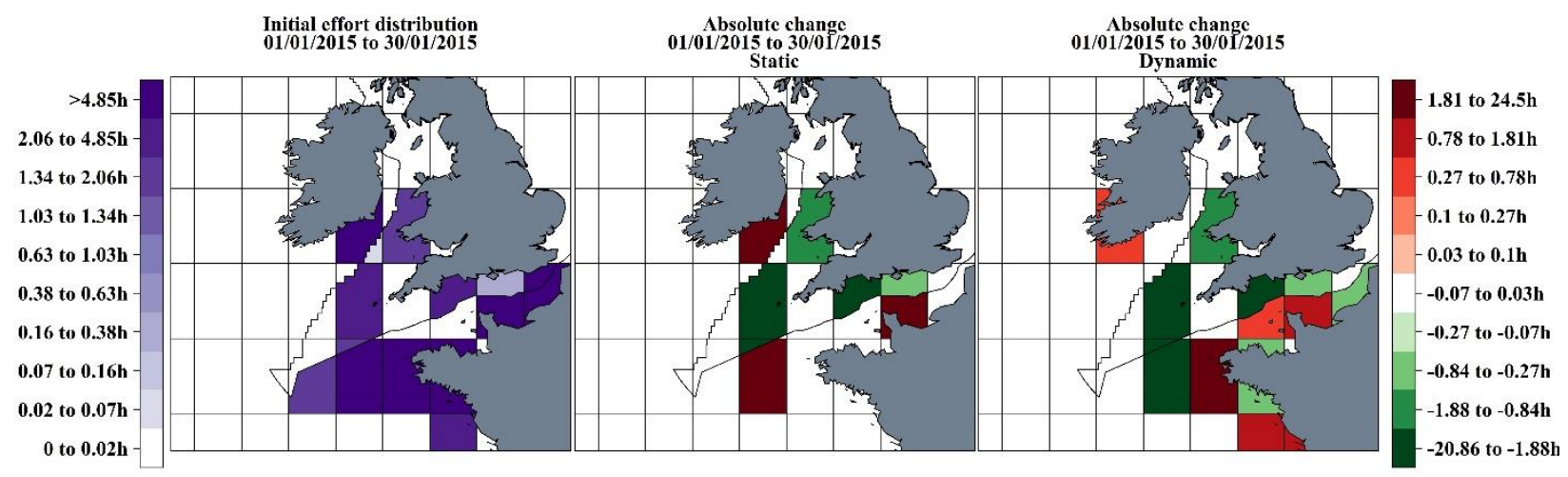

Figure E.2 Simulations of the reallocation of fishing effort due to the closure of the UK EEZ for BTR dom. $>=18 \mathrm{~m}$ vessels when using static or dynamic predictions. The left panel (left purple color key) show the spatial distribution of effort between $01 / 01 / 2015$ to $30 / 01 / 2015$. The center and right panels (right green and red color key) show the absolute change in the mean daily fishing effort (in hours of fishing) when using "static" or "dynamic" predictions. 


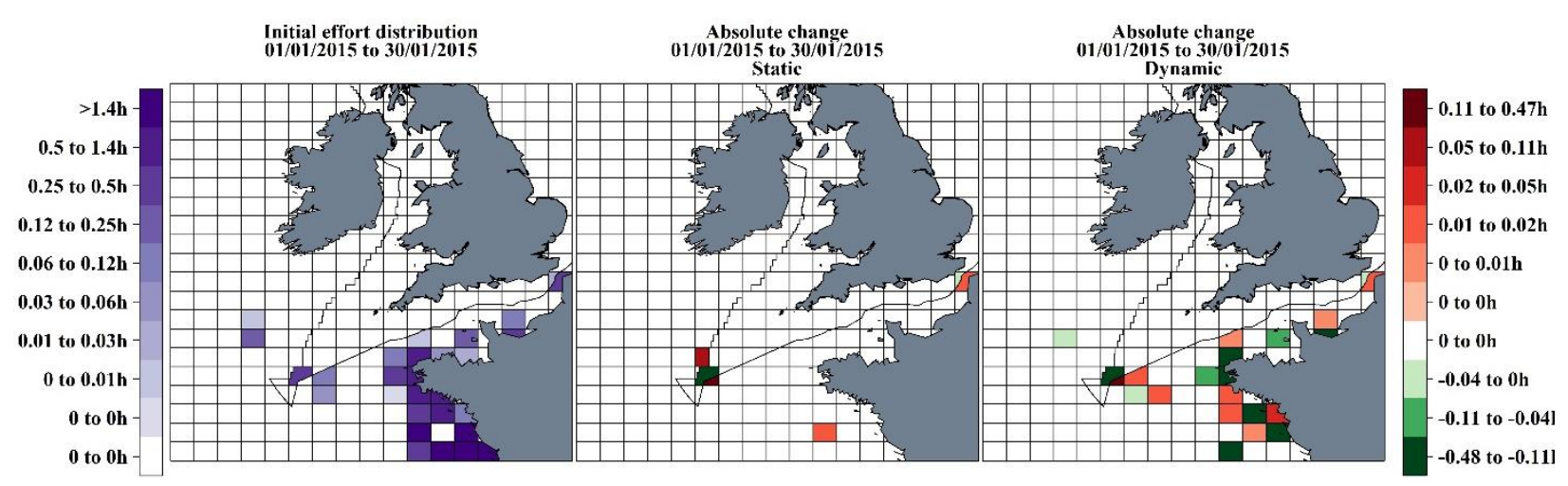

Figure E.3 Simulations of the reallocation of fishing effort due to the closure of the UK EEZ for DFN >= 12m vessels when using static or dynamic predictions. The left panel (left purple color key) show the spatial distribution of effort between $01 / 01 / 2015$ to $30 / 01 / 2015$. The center and right panels (right green and red color key) show the absolute change in the mean daily fishing effort (in hours of fishing) when using "static" or "dynamic" predictions.

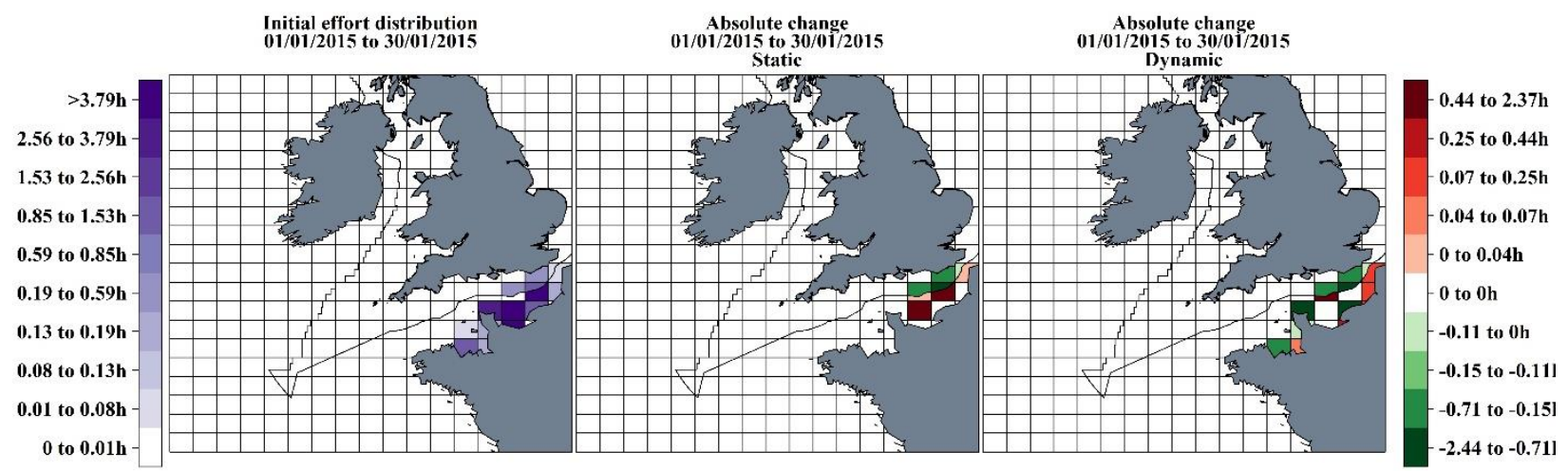

Figure E.4 Simulations of the reallocation of fishing effort due to the closure of the UK EEZ for DRD $>=12 \mathrm{~m}$ vessels when using static or dynamic predictions. The left panel (left purple color key) show the spatial distribution of effort between 01/01/2015 to 30/01/2015. The center and right panels (right green and red color key) show the absolute change in the mean daily fishing effort (in hours of fishing) when using "static" or "dynamic" predictions. 
Computing the welfare losses resulting from this reallocation the same way as in Figure 2 (i.e., using the weighted average mean of the aggregated welfare losses for each fishing ground), we obtained welfare losses that are noticeably smaller for exclusive bottom trawlers and vessels using pots and traps (about $80 \%$ smaller), moderately smaller for dominant bottom trawlers and netters (about 20\% smaller), and noticeably larger for dredgers (about 300\% larger) than the welfare losses that would be estimated without chaining the predictions (cf. Figure E.5).

While obtaining reduced losses when accounting for the dynamic behavior of fishers is expected, finding such larger losses in the case of dredgers is more surprising. A reason for that may be related to the way productivity is updated, favoring vessel-specific past productivities while this information tends to decrease the utility level of sites for this fleet segment. Another explanation could stem from the model leading to an increased concentration of the number of dredgers in the same sites, which have a particularly negative effect on utility. The inadequacy of using a $2^{\circ} \times 2^{\circ}$ resolution for this fleet segment, which is obviously too large given the initial concentration of fishing sites in the narrowest part of the Channel, may also play a role. When computing welfare losses based on ICES rectangles, the increase persists but is of a lesser magnitude, with only a $36 \%$ rise.

Note, however, that these results should be consider cautiously as the updating assumptions made to chain day-to-day predictions become weaker as the time span expands. 


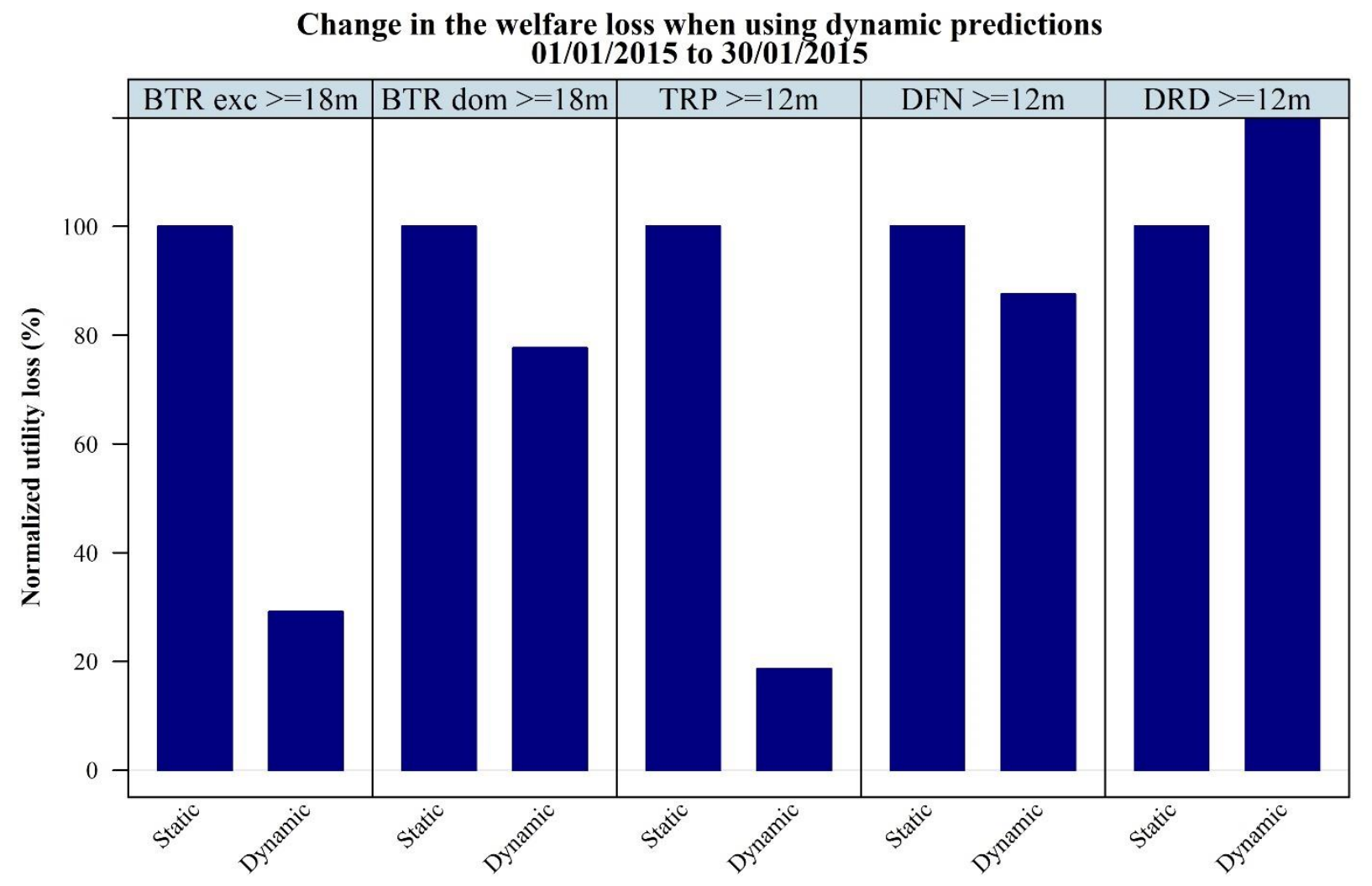

Figure E.5 Relative change in the mean welfare loss due to the closure of the UK EEZ when using dynamic predictions instead of static predictions. Welfare losses are computed only for the first 30 days of 2015 , using a $2^{\circ} \times 2^{\circ}$ resolution. The increase in the welfare loss for dredgers when using a dynamic model is $+316 \%$. 


\section{F. References for Appendix}

Abbott, J.K., Wilen, J.E., 2011. Dissecting the tragedy: A spatial model of behavior in the commons. J. Environ. Econ. Manag. 62, 386-401. https://doi.org/10.1016/j.jeem.2011.07.001

Batsleer, J., Poos, J., Marchal, P., Vermard, Y., Rijnsdorp, A., 2013. Mixed fisheries management: protecting the weakest link. Mar. Ecol. Prog. Ser. 479, 177-190. https://doi.org/10.3354/meps 10203

Branch, T.A., Hilborn, R., Haynie, A.C., Fay, G., Flynn, L., Griffiths, J., Marshall, K.N., Randall, J.K., Scheuerell, J.M., Ward, E.J., Young, M., 2006. Fleet dynamics and fishermen behavior: lessons for fisheries managers. Can. J. Fish. Aquat. Sci. 63, 16471668. https://doi.org/10.1139/f06-072

Collie, J.S., (Vic) Adamowicz, W.L., Beck, M.W., Craig, B., Essington, T.E., Fluharty, D., Rice, J., Sanchirico, J.N., 2013. Marine spatial planning in practice. Estuar. Coast. Shelf Sci. 117, 1-11. https://doi.org/10.1016/j.ecss.2012.11.010

Depalle, M., 2018. Geospatial Data and Fishery Management: Innovative Modelling Approaches. University of California, Davis, Davis.

Depalle, M., Sanchirico, J.N., Haynie, A.C., Thébaud, O., O’Farrell, S., Perruso, L., under review. Scale-dependency in discrete choice models: a fishery application (Working paper). UC Davis.

Fuller, E.C., Samhouri, J.F., Stoll, J.S., Levin, S.A., Watson, J.R., Handling editor: Robert Blasiak, 2017. Characterizing fisheries connectivity in marine social-ecological systems. ICES J. Mar. Sci. 74, 2087-2096. https://doi.org/10.1093/icesjms/fsx128

Fulton, E.A., Smith, A.D.M., Smith, D.C., van Putten, I.E., 2011. Human behaviour: the key source of uncertainty in fisheries management: Human behaviour and fisheries management. Fish Fish. 12, 2-17. https://doi.org/10.1111/j.1467-2979.2010.00371.x

Girardin, R., 2015. Ecosystem and fishers' behaviour modelling : two crucial and interacting approaches to support ecosystem based fisheries management in the eastern english channel (Thèse de doctorat). Université Lille 1.

Girardin, R., Hamon, K.G., Pinnegar, J., Poos, J.J., Thébaud, O., Tidd, A., Vermard, Y., Marchal, P., 2016. Thirty years of fleet dynamics modelling using discrete-choice models: What have we learned? Fish Fish. https://doi.org/10.1111/faf.12194

Girardin, R., Vermard, Y., Thébaud, O., Tidd, A., Marchal, P., 2015. Predicting fisher response to competition for space and resources in a mixed demersal fishery. Ocean Coast. Manag. 106, 124-135. https://doi.org/10.1016/j.ocecoaman.2015.01.017

Haab, T.C., Hicks, R.L., 1999. Choice set considerations in models of recreation demand: History and current state of the art. Mar. Resour. Econ. 14, 271-281.

Halpern, B.S., Walbridge, S., Selkoe, K.A., Kappel, C.V., Micheli, F., D’Agrosa, C., Bruno, J.F., Casey, K.S., Ebert, C., Fox, H.E., Fujita, R., Heinemann, D., Lenihan, H.S., Madin, E.M.P., Perry, M.T., Selig, E.R., Spalding, M., Steneck, R., Watson, R., 2008. A Global Map of Human Impact on Marine Ecosystems. Science 319, 948-952. https://doi.org/10.1126/science.1149345

Haynie, A.C., Layton, F.D., 2010. An expected profit model for monetizing fishing location choices. J. Environ. Econ. Manag. 59, 165-176. https://doi.org/10.1016/j.jeem.2009.11.001 
Huang, A., Levinson, D., 2015. Axis of travel: Modeling non-work destination choice with GPS data. Transp. Res. Part C Emerg. Technol. 58, 208-223. https://doi.org/10.1016/j.trc.2015.03.022

Huang, L., Smith, M.D., 2014. The Dynamic Efficiency Costs of Common-Pool Resource Exploitation. Am. Econ. Rev. 104, 4071-4103. https://doi.org/10.1257/aer.104.12.4071

Hutniczak, B., Münch, A., 2018. Fishermen's location choice under spatio-temporal update of expectations. J. Choice Model. 28, 124-136. https://doi.org/10.1016/j.jocm.2018.05.002

Hynes, S., Gerritsen, H., Breen, B., Johnson, M., 2016. Discrete choice modelling of fisheries with nuanced spatial information. Mar. Policy 72, 156-165. https://doi.org/10.1016/j.marpol.2016.07.004

Jones, J., Thomas, I., Peeters, D., 2015. Forecasting jobs location choices by Discrete Choice Models: A sensitivity analysis to scale and implications for LUTI models. Region 2, 6793.

Jones, P.J.S., 2016. Marine spatial planning in reality_ Introduction to case studies and discussion of findings. Mar. Policy 9.

Kuriyama, P.T., Holland, D.S., Barnett, L.A.K., Branch, T.A., Hicks, R.L., Schnier, K.E., 2019. Catch shares drive fleet consolidation and increased targeting but not spatial effort concentration nor changes in location choice in a multispecies trawl fishery. Can. J. Fish. Aquat. Sci. https://doi.org/10.1139/cjfas-2019-0005

Manski, C.F., 1977. The structure of random utility models. Theory Decis. 8, 229-254. https://doi.org/10.1007/BF00133443

Mateo, M., Pawlowski, L., Robert, M., 2016. Highly mixed fisheries: fine-scale spatial patterns in retained catches of French fisheries in the Celtic Sea. ICES J. Mar. Sci. J. Cons. fsw129. https://doi.org/10.1093/icesjms/fsw129

McFadden, D., 1974. Conditional Logit Analysis of Qualitative Choice Behaviour, in: Frontiers in Econometrics. Zarembka, New York.

Parsons, G.R., Hauber, A.B., 1998. Spatial Boundaries and Choice Set Definition in a Random Utility Model of Recreation Demand. Land Econ. 74, 32. https://doi.org/10.2307/3147211

Poos, J.-J., Rijnsdorp, A.D., 2007. An "experiment" on effort allocation of fishing vessels: the role of interference competition and area specialization. Can. J. Fish. Aquat. Sci. 64, 304313. https://doi.org/10.1139/f06-177

Rijnsdorp, A.D., Poos, J.J., Quirijns, F.J., Grant, J., 2011. Spatial dimension and exploitation dynamics of local fishing grounds by fishers targeting several flatfish species. Can. J. Fish. Aquat. Sci. 68, 1064-1076. https://doi.org/10.1139/f2011-032

Russo, T., Pulcinella, J., Parisi, A., Martinelli, M., Belardinelli, A., Santojanni, A., Cataudella, S., Colella, S., Anderlini, L., 2015. Modelling the strategy of mid-water trawlers targeting small pelagic fish in the Adriatic Sea and its drivers. Ecol. Model. 300, 102-113. https://doi.org/10.1016/j.ecolmodel.2014.12.001

SACROIS [WWW Document], 2017. . Système Inf. Halieut. URL http://sih.ifremer.fr/Description-des-donnees/Donnees-estimees/SACROIS

Sanchirico, J.N., Eagle, J., Palumbi, S., Jr, B.H.T., 2010. Comprehensive Planning, DominantUse-Zones, and User Rights: a New Era in Ocean Governance. Bull. Mar. Sci. 86, 15.

Sanchirico, J.N., Wilen, J.E., 1999. Bioeconomics of Spatial Exploitation in a Patchy Environment. J. Environ. Econ. Manag. 37, 129-150. https://doi.org/10.1006/jeem.1998.1060 
Scott, A., 1955. The fishery: the objectives of sole ownership. J. Polit. Econ. 116-124.

Sievanen, L., Leslie, H.M., Wondolleck, J.M., Yaffee, S.L., McLeod, K.L., Campbell, L.M., 2011. Linking topdown and bottomup processes through the new U.S. National Ocean Policy. Conserv. Lett. 6.

Simons, S.L., Doring, R., Temming, A., 2015. Modelling fishers' response to discard prevention strategies: the case of the North Sea saithe fishery. ICES J. Mar. Sci. 72, 1530-1544. https://doi.org/10.1093/icesjms/fsu229

Smith, M.D., 2010. Toward an econometric foundation for marine ecosystem-based management. Bull. Mar. Sci. 86, 461-477.

Smith, M.D., 2005. State dependence and heterogeneity in fishing location choice. J. Environ. Econ. Manag. 50, 319-340. https://doi.org/10.1016/j.jeem.2005.04.001

Smith, M.D., Sanchirico, J.N., Wilen, J.E., 2009. The economics of spatial-dynamic processes: Applications to renewable resources. J. Environ. Econ. Manag., Frontiers of Environmental and Resource Economics 57, 104-121. https://doi.org/10.1016/j.jeem.2008.08.001

von Haefen, R.H., 2008. Latent Consideration Sets and Continuous Demand Systems. Environ. Resour. Econ. 41, 363-379. https://doi.org/10.1007/s10640-008-9196-x 